ARTICLE

https://doi.org/10.1038/s41467-019-09453-x

\title{
Integrin activation by the lipid molecule 25-hydroxycholesterol induces a proinflammatory response
}

Swechha M. Pokharel ${ }^{1}$, Niraj K. Shil ${ }^{1}$, Jeevan B. GC ${ }^{2}$, Zachary T. Colburn ${ }^{3}$, Su-Yu Tsai ${ }^{4}$, Jesus A. Segovia ${ }^{4}$, Te-Hung Chang ${ }^{4}$, Smarajit Bandyopadhyay ${ }^{5}$, Senthil Natesan $\mathbb{D}^{2}$, Jonathan C.R. Jones $\mathbb{B}^{3}$ \& Santanu Bose ${ }^{1}$

Integrins are components of cell-matrix adhesions, and function as scaffolds for various signal transduction pathways. So far no lipid ligand for integrin has been reported. Here we show that a lipid, oxysterol 25-hydroxycholesterol (25HC), directly binds to $\alpha 5 \beta 1$ and $\alpha v \beta 3$ integrins to activate integrin-focal adhesion kinase (FAK) signaling. Treatment of macrophages and epithelial cells with $25 \mathrm{HC}$ results in an increase in activated $\alpha v \beta 3$ integrin in podosome and focal adhesion matrix adhesion sites. Moreover, activation of pattern recognition receptor on macrophages induces secretion of $25 \mathrm{HC}$, triggering integrin signaling and the production of proinflammatory cytokines such as TNF and IL-6. Thus, the lipid molecule $25 \mathrm{HC}$ is a physiologically relevant activator of integrins and is involved in positively regulating proinflammatory responses. Our data suggest that extracellular $25 \mathrm{HC}$ links innate immune inflammatory response with integrin signaling.

\footnotetext{
${ }^{1}$ Department of Veterinary Microbiology and Pathology, Washington State University, Pullman, WA 99163, USA. ${ }^{2}$ Department of Pharmaceutical Sciences, College of Pharmacy and Pharmaceuticals Sciences, Washington State University, Spokane, WA 99210, USA. ${ }^{3}$ School of Molecular Biosciences, Washington State University, Pullman, WA 99163, USA. ${ }^{4}$ Department of Microbiology and Immunology, The University of Texas Health Science Center at San Antonio, San Antonio, TX 78229, USA. ${ }^{5}$ Molecular Biotechnology Core Laboratory, Lerner Research Institute, Cleveland Clinic, Cleveland, OH 44195, USA. These authors contributed equally: Swechha M. Pokharel, Niraj K. Shil. These authors jointly supervised this work: Senthil Natesan, Jonathan C.R. Jones, Santanu Bose. Correspondence and requests for materials should be addressed to S.B. (email: santanu.bose@wsu.edu)
} 
ntegrins, heterodimeric transmembrane receptors composed of one $\alpha$ - and one $\beta$-subunit, regulate numerous biological processes, including extracellular matrix assembly, cell adhesion, and cell migration ${ }^{1-3}$. In conjunction with a variety of associated proteins, integrin heterodimers function as signaling hubs, mediating both inside-out and outside-in signal transduction $^{3-5}$. The ability of an integrin to signal depends on its conformational state $\mathrm{b}^{6-10}$. Integrins cluster, forming a variety of matrix attachment sites, including focal adhesions (FAs) and/or podosomes ${ }^{11}$. FAs and podosomes contain many proteins, tether the cell to the extracellular matrix, function as membrane attachment sites for the actin cytoskeleton, are involved in cell motility and invasion, and act to scaffold integrin-mediated signaling events ${ }^{12}$. The latter are involved in numerous pathways, some of which lead to changes in gene expression via the actions of transcription factors such as MAPK and NFKB which, in turn, regulate various cellular functions, including the proinflammatory response and inflammation during innate immunity, the subject of this study ${ }^{12}$.

The innate immune system is an important host defense against pathogens (viruses, bacteria, fungi, and parasites), is also involved in the pathogenesis of various "non-infectious" inflammatory diseases, and depends, at least in part, on pattern recognition receptor (PRR) activation by pathogen associated molecular patterns (PAMPs) ${ }^{13}$. PRRs are expressed by cells of the innate immune system, including macrophages and certain epithelial cells. PRR activation by PAMPs represents the sentinel cellular mechanism triggering innate immunity and inflammatory response during infection. Nucleotide-binding oligomerization domain-containing protein $2(\mathrm{Nod} 2)$ is a cytosolic PRR involved in innate immune inflammatory response during infection by viruses and bacteria and its hallmark function is to activate the NFkB signaling pathway, which promotes expression and production of a proinflammatory cytokine network ${ }^{14-21}$.

Numerous integrin ligands have been identified, including components of the extracellular matrix, counter-receptors on the surface of adjacent cells, certain growth factors, and members of the ADAM (a disintegrin and metalloproteinase) protein family 22,23 . However, a lipid ligand for integrins has not been reported.

In the current study, we identify 25-hydroxycholesterol (25HC), an oxygenated metabolite of cholesterol (oxysterol) catalyzed by the enzyme cholesterol 25 -hydroxylase $(\mathrm{C} 25 \mathrm{H})$ as a lipid ligand of integrins. $25 \mathrm{HC}$ directly interacts with integrins to trigger focal adhesion kinase (FAK) activation. In addition, we identify the $25 \mathrm{HC}$-related signaling network involved in optimizing the proinflammatory response following activation of the PRR Nod2. Our data, thus, show that extracellular 25HC, released from PRR-activated cells, is a molecular link bridging the PRR pathway and integrin-FAK signaling.

\section{Results}

25HC activates FAK signaling. 25HC (Fig. 1a) is an oxygenated metabolite (oxysterol) of cholesterol catalyzed by the enzyme cholesterol 25-hydroxylase $(\mathrm{C} 25 \mathrm{H})^{24,25}$. A recent study provided evidence that soluble (extracellular) 25HC activates a proinflammatory response in macrophages however the mechanism by which it does so was not elucidated ${ }^{26}$. Nonetheless, intracellular signaling induced by extracellular $25 \mathrm{HC}$ is likely a consequence of its binding to a membrane signaling receptor. While there are a number of candidate receptors, previous reports demonstrating a role of integrin-FAK signaling in inducing proinflammatory response led us to hypothesize that activation of integrin-FAK signaling by $25 \mathrm{HC}$ may represent the molecular mechanism driving the proinflammatory activity of $25 \mathrm{HC}^{27,28}$. FAK is a key adaptor protein in integrin-mediated signal transduction pathways ${ }^{1,2}$. Therefore, we first investigated whether $25 \mathrm{HC}$ activates FAK and the role of activated FAK in mediating the 25HCdependent proinflammatory response.

Phosphorylation of FAK (at tyrosine residues) is an indicator of its activation and is a consequence of integrin signaling ${ }^{1,2}$. Treatment of macrophages with $25 \mathrm{HC}$ triggered FAK phosphorylation as detected by western blot analyses (Fig. 1b). Densitometric analyses of the phospho-FAK western blot data revealed significant induction of FAK following 25HC treatment (Fig. 1b). We next assessed whether FAK activation played a role in $25 \mathrm{HC}$ mediated induction of the proinflammatory response by assaying secretion of the proinflammatory cytokines TNF- $\alpha$ (TNF) and IL6 in cells expressing FAK, as well as in cells in which FAK was absent or inhibited. We focused our studies on these two cytokines as they are critical proinflammatory mediators that shape innate inflammatory responses during various infectious (e.g., viral, bacterial) and non-infectious diseases/conditions such as arthritis. Surprisingly, there was a complete abrogation of IL-6 secretion in 25HC-treated FAK knockout (KO) mouse embryo fibroblasts (MEFs) (Fig. 1c). Moreover, the inhibition of FAK activity in macrophages drastically reduced the $25 \mathrm{HC}$-induced production of both TNF and IL-6 (Fig. 1d and Supplementary Fig. 1a). Lactate dehydrogenase (LDH) cytotoxicity assays revealed negligible loss of cell viability in 25HC-treated FAK $\mathrm{KO}$ macrophages or macrophages treated with a FAK inhibitor (Supplementary Table 1).

As FAK signaling activated a number of downstream molecules, including NFkB, we evaluated whether NFkB mediates the cellular response to $25 \mathrm{HC}$ treatment. BAY-11, an NFkB inhibitor, reduced TNF and IL-6 secretion from macrophages treated with $25 \mathrm{HC}$ (Fig. 1e and Supplementary Fig. 1b). This result was further validated as TNF production was reduced by $66 \%$ in $25 \mathrm{HC}$-treated NFkB KO (NFkB p105 KO) primary bone marrow-derived macrophages (BMDMs) (Fig. 1f). Accordingly, $\mathrm{NF \kappa B}$ activation was diminished in 25HC-treated FAK KO cells, evaluated by western blot to assess the levels of phosphorylated

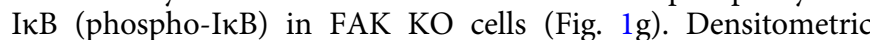
analyses of the phospho-I $\kappa \mathrm{B}$ western blot data revealed significant induction of NFKB (i.e., increased phospho-IKB levels) in 25HCtreated wild-type (WT) cells, but not in FAK KO cells (Fig. 1g). Thus, our studies have identified a previously unknown signal transduction network in which $25 \mathrm{HC}$ activates FAK-NFkB signaling.

25HC binds integrins $\alpha 5 \beta 1$ and $\alpha v \beta 3$. As integrin activation triggers FAK activation ${ }^{1,2}$, we next assayed whether $25 \mathrm{HC}$ associates with integrins. To that end, we generated biotin labeled $25 \mathrm{HC}$ (biotinylated $25 \mathrm{HC}$ or biotin-25HC) and confirmed the latter was indeed biotinylated and active in triggering proinflammatory response (Supplementary Fig. 2a, b). We incubated chilled BMDMs with biotin-25HC (at $4^{\circ} \mathrm{C}$ ) to promote $25 \mathrm{HC}$ interaction with cell surface moieties in the absence of their internalization. Following incubation, protein complexes were precipitated with avidin-agarose and subjected to western blot analyses with a5 integrin antibody. $25 \mathrm{HC}$, but not DMSO treatment, precipitated $\alpha 5$ integrin, indicating an association between $25 \mathrm{HC}$ and a5 integrin subunit-containing complexes on the cell surface (Fig. 2a). A similar experiment with chilled RAW 264.7 macrophages also revealed interaction of biotin-25HC with cell surface av integrin subunits (Fig. 2b).

Next, in vitro binding assays were performed to examine whether $25 \mathrm{HC}$ directly interacts with purified integrin heterodimers. Biotin-25HC conjugated to avidin-agarose beads was incubated with either purified $\alpha 5 \beta 1$ or $\alpha v \beta 3$ integrin 
a<smiles>CC(CCCC(C)(C)O)C1CCC2(C)CCC3(C)C4CCC(O)CC4=CCC23C1</smiles>

b

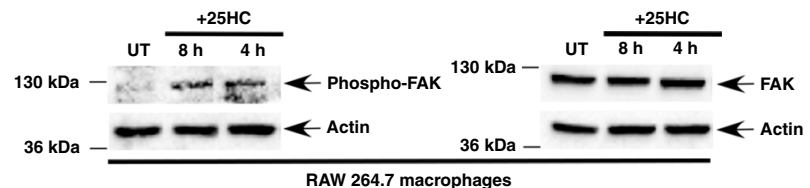

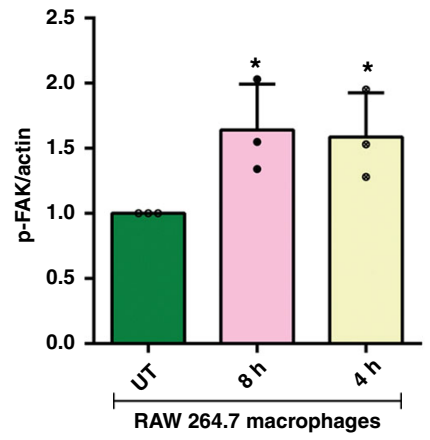

C

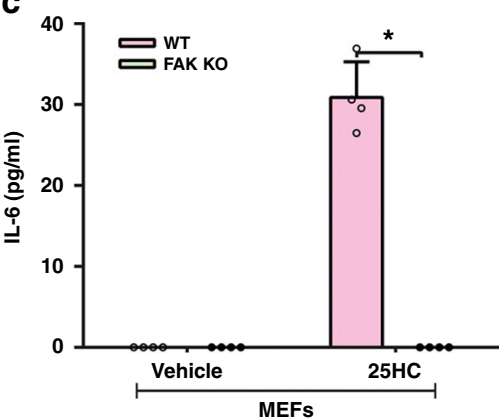

e

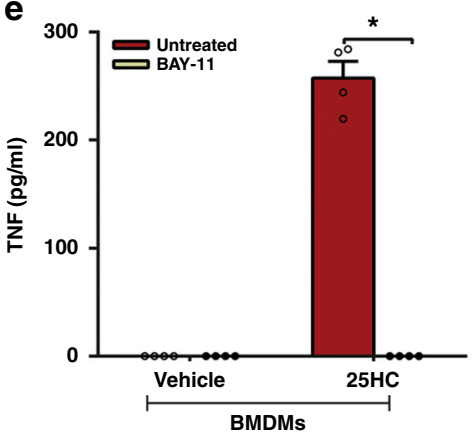

d

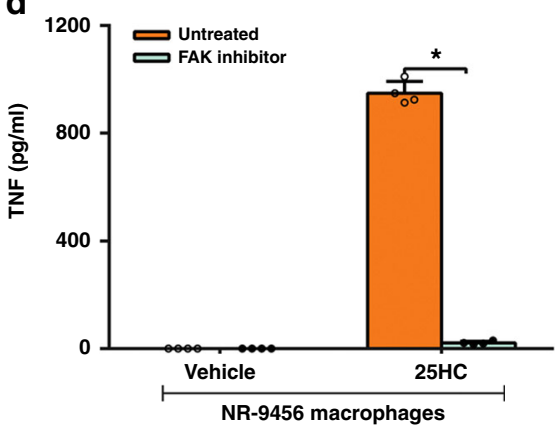

f

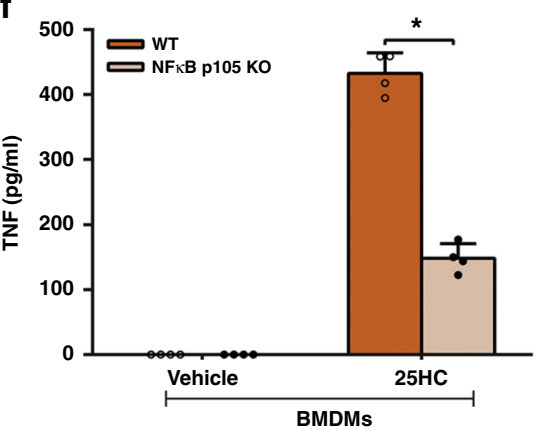

g
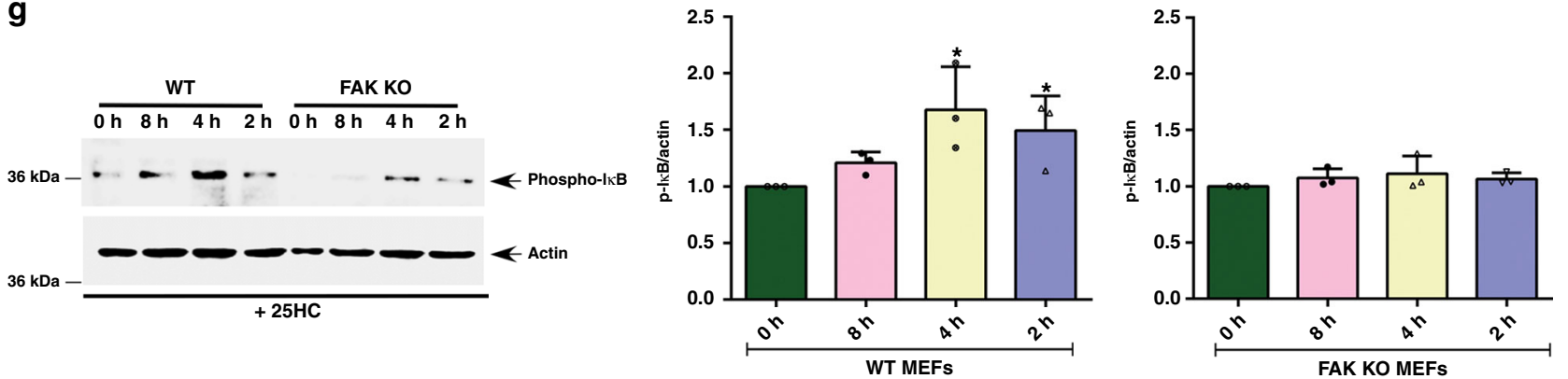

Fig. $1 \mathrm{FAK}-\mathrm{NF \kappa B}$ pathway is required for $25 \mathrm{HC}$-dependent proinflammatory response. a Structure of 25 -hydroxycholesterol (25HC). b-g Cells were treated with $50 \mu \mathrm{M} 25 \mathrm{HC}$ for $8 \mathrm{~h}$. FAK and NFKB activation and proinflammatory response in treated cells were evaluated. $\mathbf{b}$ Western blot and densitometric analyses of FAK activation (phospho-FAK, Tyr925) status in 25HC-treated RAW 264.7 macrophages. c IL-6 secretion from wild-type (WT) and FAK knockout (KO) MEFs (mouse embryo fibroblasts) treated with 25HC. d TNF secretion from NR-9456 macrophages treated with $25 \mathrm{HC}$ in the absence or presence of FAK inhibitor $(5 \mu \mathrm{M})$. e TNF secretion from BMDMs treated with $25 \mathrm{HC}$ in the absence or presence of NFKB inhibitor Bay 11-7082 (BAY-11) $(10 \mu \mathrm{M})$. f TNF secretion from WT and NFKB p105 KO BMDMs treated with 25HC. $\mathbf{g}$ Western blot and densitometric analyses of phospho-IKB status in 25HC-treated WT and FAK KO MEFs. The ELISA values (mean \pm standard deviation) are representative from two or three independent experiments $(n=4)$. ${ }^{*} p \leq 0.05$ using a Student's $t$-test. The densitometric quantification values for phospho-FAK ( $\left.p-F A K\right)$ and phospho-IKB ( $p$ - IKB) immunoblots represent the ratio of phospho-FAK:actin and phospho-IKB:actin and the fold-induction was calculated after normalizing with the control untreated (UT) or control $\mathrm{O}$ h group. The densitometric values represent the mean \pm standard deviation from three independent studies. ${ }^{*} p \leq 0.05$ using a Student's $t$-test

(Supplementary Fig. 2c) and the complex was subjected to western blotting with either a5 or av integrin antibodies. Our studies revealed direct association of $25 \mathrm{HC}$ with both $\alpha 5 \beta 1$ and av 33 integrins (Fig. 2c, d). Finally, we corroborated these findings using tritiated-25HC $\left({ }^{3} \mathrm{H}-25 \mathrm{HC}\right) .{ }^{3} \mathrm{H}-25 \mathrm{HC}$ was active as it triggered a proinflammatory response in macrophages (Supplementary Fig. 2d). Protein G-agarose beads were conjugated with either control IgG or antibody specific for $a 5$ and av integrin heterodimers, which were subsequently incubated with purified $\alpha 5 \beta 1$ or $\alpha v \beta 3$ integrin, respectively. Control beads and integrin 

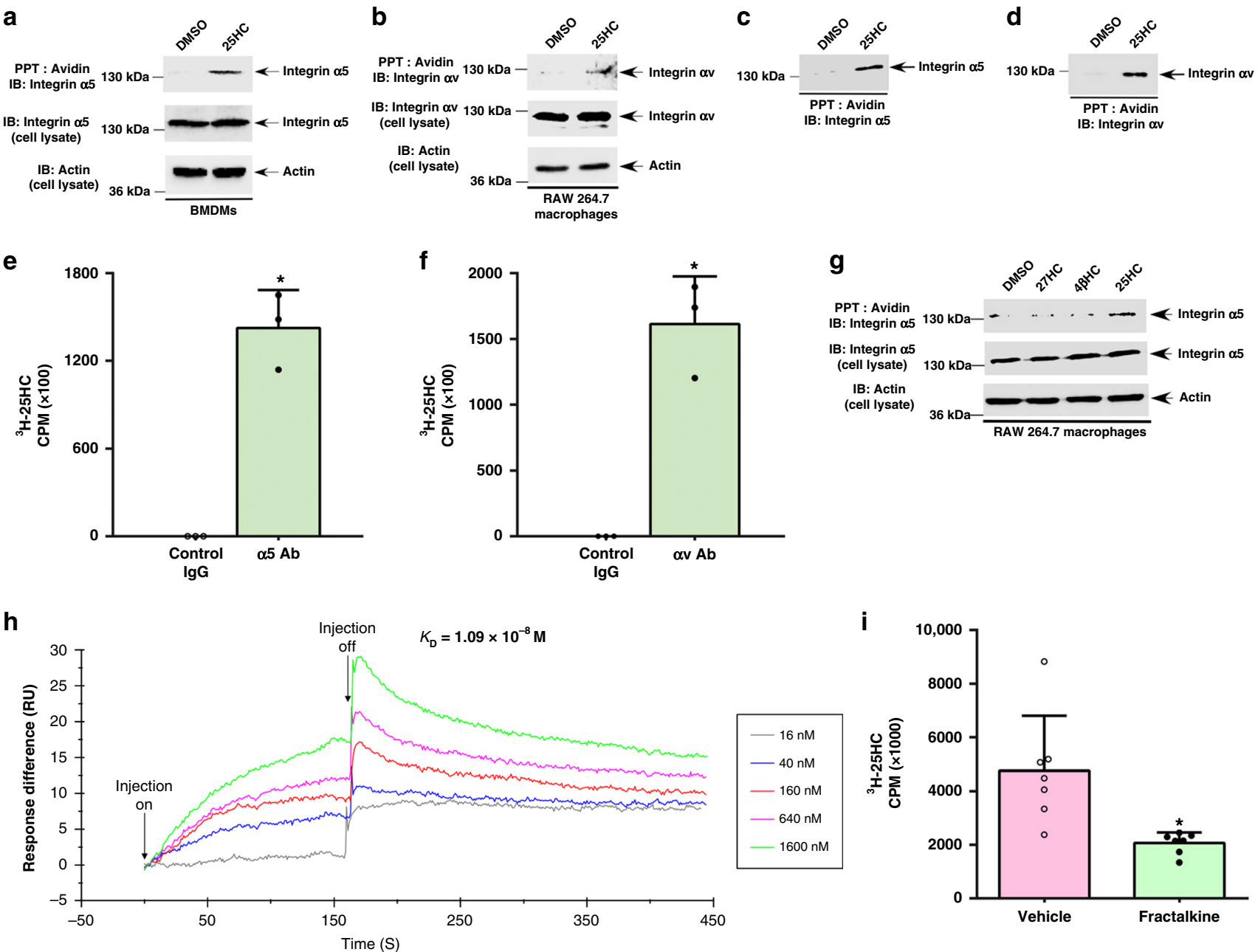

Fig. $225 \mathrm{HC}$ interacts with $\alpha 5 \beta 1$ and $\alpha v \beta 3$ integrins. a, b Biotinylation reactions were performed in the presence of either $25 \mathrm{HC}$ or DMSO (control). Cell lysates collected from BMDMs (a) or RAW 264.7 macrophages (b) incubated with biotinylated $25 \mathrm{HC}$ (biotin-25HC) or DMSO at $4{ }^{\circ} \mathrm{C}$ were precipitated (PPT) with avidin-agarose and subsequently immuno-blotted (IB) with either $\alpha 5$ integrin (a) or $\alpha v$ integrin (b) antibody. Total lysates were also blotted with $\alpha 5$ integrin (a), $\alpha v$ integrin (b), and actin (a, b) antibodies. c, d Biotin-25HC and DMSO (control) were incubated (PPT; precipitated) with avidin-agarose beads. $25 \mathrm{HC}$ conjugated beads were then incubated either with purified $\alpha 5 \beta 1$ integrin (c) or $\alpha v \beta 3$ integrin (d). The avidin-agarose bound complex was subsequently immuno-blotted with either $\alpha 5$ integrin (c) or $\alpha v$ integrin (d) antibody. e, $\mathbf{f}$ Protein G-agarose beads were conjugated with either control IgG or antibody (Ab) specific for $\alpha 5$ integrin (e) and $\alpha v$ integrin (f). The beads were then incubated with either purified $\alpha 5 \beta 1$ integrin (e) or $\alpha v \beta 3$ integrin (f) protein. Control beads (control lgG + purified integrin protein) and integrin protein bound beads (integrin-specific antibody + purified integrin protein) was incubated with tritiated ${ }^{3} \mathrm{H}-25 \mathrm{HC}$. Bead-bound radioactivity (count per minute; $\mathrm{CPM}$ ) was measured by scintillation counter. $\mathbf{g}$ Cell lysate collected from RAW 264.7 macrophages incubated with biotin-25HC, biotinylated 27-hydroxycholesterol (biotin-27HC), biotinylated 4 $\beta$ -

hydroxycholesterol (biotin- $4 \beta \mathrm{HC}$ ) or DMSO (control) at $4{ }^{\circ} \mathrm{C}$ was precipitated (PPT) with avidin-agarose and subsequently immuno-blotted with $\alpha 5$ integrin antibody. Total cell lysate was also blotted with $\alpha 5$ integrin and $\beta$-actin antibodies. $\mathbf{h}$ Surface plasmon resonance (SPR) analyses were performed by injecting increasing concentrations of $25 \mathrm{HC}(16 \mathrm{nM}, 40 \mathrm{nM}, 160 \mathrm{nM}, 640 \mathrm{nM}, 1.6 \mu \mathrm{M})$ into both the $\alpha v \beta 3$ integrin-immobilized and control surface of the CM5 chips. Each background-corrected sensorgram is a representative of replicate runs. $\mathbf{i}$ Binding of radioactive ${ }^{3} \mathrm{H}-25 \mathrm{HC}$ to immobilized $\alpha v \beta 3$ integrin protein in the presence or absence of purified chemokine domain of fractalkine protein was assessed as described in the "methods" section. Immunoblot images are representative from three independent experiments. The radioactive values (mean \pm standard deviation) are representative from two independent experiments. ${ }^{*} p \leq 0.05$ using a Student's $t$-test

protein-bound beads were then incubated with ${ }^{3} \mathrm{H}-25 \mathrm{HC}$. We detected binding of radioactive $25 \mathrm{HC}$ to both purified $\alpha 5 \beta 1$ and $\alpha v \beta 3$ integrins (Fig. 2e, f). The interaction of $25 \mathrm{HC}$ with integrin was specific as our in vivo studies revealed that two closely related oxysterols, 27-hydroxycholesterol (27HC) and $4 \beta$ hydroxycholesterol $(4 \beta \mathrm{HC})$, failed to interact with cell surface $\alpha 5$ integrin subunits, in contrast to $25 \mathrm{HC}$ (Fig. $2 \mathrm{~g}$ ).

We further confirmed the specificity of $25 \mathrm{HC}$-integrin interaction by two distinct methods, (a) surface plasmon resonance (SPR), and (b) competitive binding assay. In these two studies we analyzed the interaction of $25 \mathrm{HC}$ with av 33 integrin, as av $\beta 3$ integrin interacts with $25 \mathrm{HC}$ (Fig. 2b, d, f) and, more importantly, our molecular dynamics (MD) study (Fig. 3, below) suggested specific binding of $25 \mathrm{HC}$ to site-II of av 33 integrin. First we performed SPR analyses by using a sensor chip in which av $\beta 3$ integrin protein was immobilized. The specificity of $25 \mathrm{HC}$-integrin interaction was borne out by the observation that $25 \mathrm{HC}$ bound to $\alpha v \beta 3$ integrin at a high-affinity (equilibrium dissociation constant or $K_{\mathrm{D}}$ of $1.09 \times 10^{-8} \mathrm{M}$ or $10.9 \mathrm{nM}$ ) (Fig. 2h). Interestingly, the $K_{\mathrm{D}}$ value of $25 \mathrm{HC}$-intigrin was comparable to the SPR-derived $K_{\mathrm{D}}$ values reported for binding of integrin molecules with its matrix and growth factor ligands, 

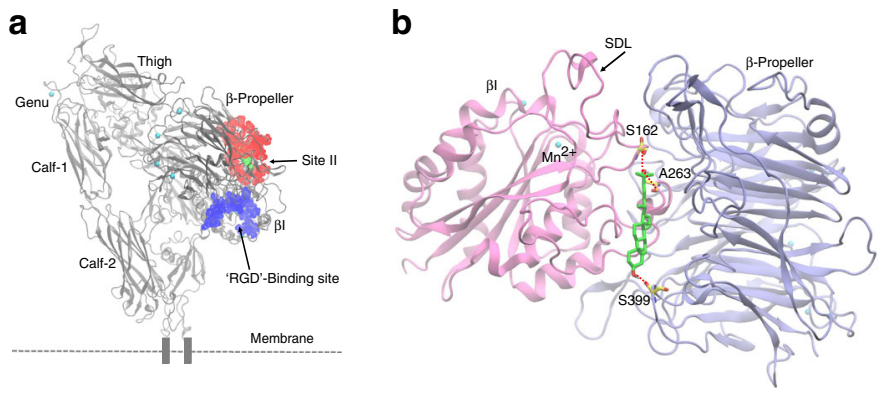

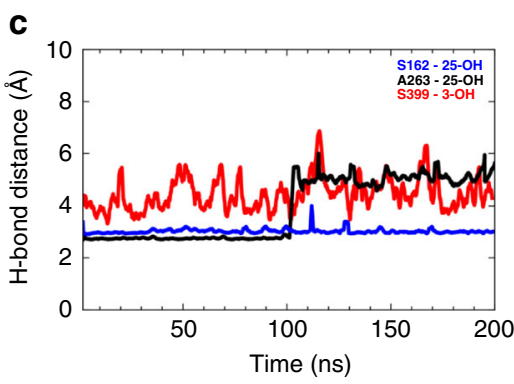

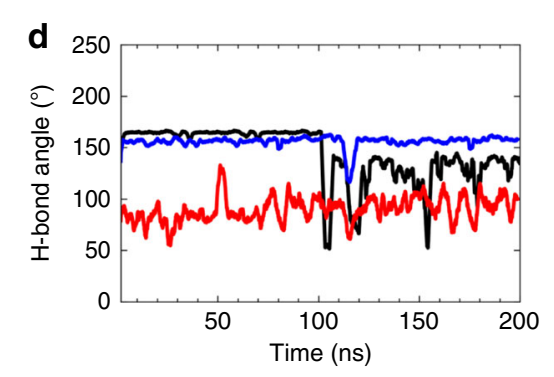

f

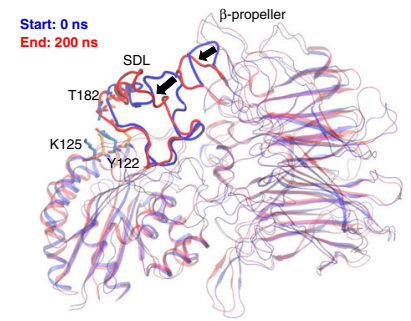

h

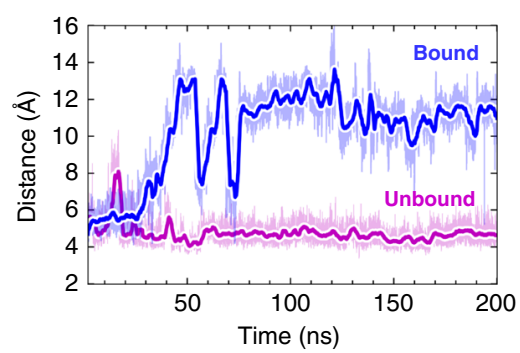

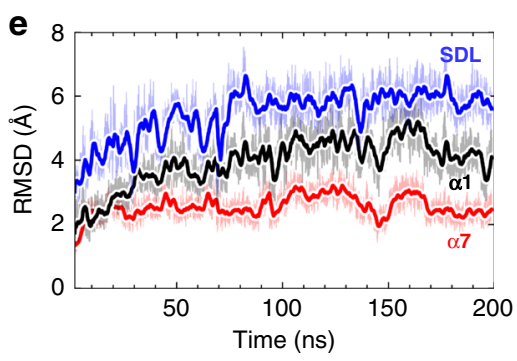

g

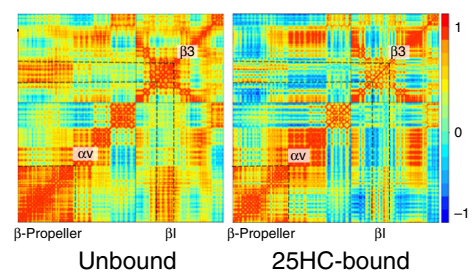

i

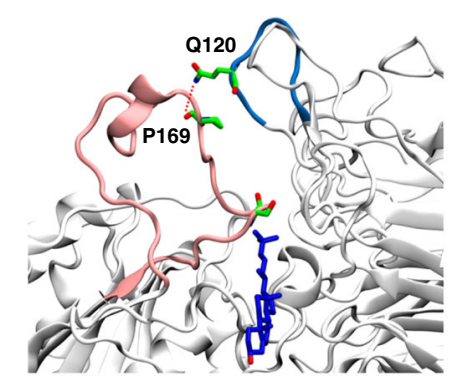

Fig. 3 Modeling identifies specific interactions between $\alpha v \beta 3$ integrin and $25 \mathrm{HC}$. a Ectodomain structure of $\alpha v \beta 3$ integrin containing 'RGD'-binding site (site I) (blue) and site-II (red) residues highlighted by a layer of solvent molecule of radius $1.4 \AA$. The site-II-bound $25 \mathrm{HC}$ molecule is presented as a surface model in green and $\mathrm{Mn}^{2+}$ ions from metal-ion-dependent ligand-binding site (MIDAS) and adjacent to MIDAS (ADMIDAS) sites of $\beta$ I domain, $\beta$-propeller domain and genu knee region are presented in cyan. $\mathbf{b}$ Potential interacting residues for molecular recognition of $\alpha \vee \beta 3$ integrin by $25 \mathrm{HC}$ were identified in a docking simulation. $\mathrm{H}$-bonds are highlighted in dashed lines in red. c, d Ser399 of $\beta$-propeller (red), Ser162 (blue) and Ala263 (black) of $\beta$ I domain make stable $\mathrm{H}$-bond interactions with 3- and 25-hydroxyl groups of $25 \mathrm{HC}$, respectively. The H-bond distances (c) and $\mathrm{H}$-bond angles (d) are plotted against MD simulation time (200 ns). e The root-mean-square deviations (RMSD) measured for specificity-determining loop (SDL), $\alpha 1-$ and $\alpha 7$ helices during the entire $200 \mathrm{~ns}$ long simulation. The SDL region undergoes significant conformational change (RMSD of $\sim 6 \AA$ ) upon $25 \mathrm{HC}$ binding. $\mathbf{f}$ The conformational change in the SDL is accompanied by disruption of $\mathrm{H}$-bond interaction between Tyr122-Thr182 residues, as well as change in the $\beta$-propeller blade that interacts with SDL. Movement of the regions from the beginning $0 \mathrm{~ns}$ (blue) to the end $200 \mathrm{~ns}$ (red) is indicated by arrows. $\mathbf{g}$ Correlation matrices (as heat maps) indicating correlated (red) or anti-correlated motions (blue) of $\alpha$ - and $\beta$-subunits of $\alpha v \beta 3$ integrin in unbound and $25 \mathrm{HC}$-bound states. $\mathbf{h}$, $\mathbf{i}$ The distance between the amide $\mathrm{NH}$ of Q120 of the $\beta$-propeller domain and backbone carbonyl oxygen of P169 of the SDL. Breakage of this electrostatic interaction in the $25 \mathrm{HC}$-bound protein (blue) during the simulation, around $\sim 30$ ns simulation causes significant increase in the distance, which remain intact in the unbound protein (magenta) during the entire 200 ns simulation time

including fibronectin $\left[K_{\mathrm{D}}=4.4 \mathrm{nM}\right.$ for $\alpha 5 \beta 1$-fibronectin binding $\left.^{29}\right]$, collagen- $\mathrm{I}\left[K_{\mathrm{D}}=24 \mathrm{nM}\right.$ for $\alpha 1 \beta 1$-collagen binding $\left.{ }^{30}\right]$, vitronectin $\left[K_{\mathrm{D}}=64 \mathrm{nM}\right.$ for $\operatorname{av} \beta 3$-vitronectin binding $\left.{ }^{31}\right]$, and insulin like growth factor-1 or IGF1 $\left[K_{\mathrm{D}}=31 \mathrm{nM}\right.$ for $\operatorname{av} \beta 3$-IGF1 binding ${ }^{32}$. Interestingly, 25HC-av $\beta 3$ integrin affinity (Fig. $2 \mathrm{~h}$ ) was comparable to that of other molecules that interact with
site-II of av $\beta 3$ integrin, including phospholipase A2 $\left(K_{\mathrm{D}}=211\right.$ $\mathrm{nM}$ for av $\beta 3$-phospholipase A2 binding to site-II $)^{33}$ and fractalkine $\left(K_{\mathrm{D}}=0.3 \mathrm{nM}-6.9 \mathrm{nM}\right.$ for $\alpha \mathrm{v} \beta 3$-fractalkine binding to site-II) ${ }^{34}$. Thus, our SPR results showing high-affinity binding of $25 \mathrm{HC}$ with integrin demonstrated that $25 \mathrm{HC}$-intgerin interaction is highly specific. 
We next performed a modified "ELISA-type" 25HC-integrinbinding assay ${ }^{34-36}$. As our MD studies (Fig. 3, below) revealed binding of $25 \mathrm{HC}$ to the site-II of av $\beta 3$ integrin, we choose fractalkine protein as a competitor since previous studies have shown that the chemokine domain (CD) of fractalkine protein (fractalkine-CD) binds to the site-II of av 33 integrin ${ }^{34,35}$. Plates were coated with purified av $\beta 3$ integrin protein followed by addition of tritiated-25HC $\left({ }^{3} \mathrm{H}-25 \mathrm{HC}\right)$. In some experiments, immobilized av $\beta 3$ integrin was first incubated with purified fractalkine-CD protein $(\sim 9 \mathrm{kDa})$ (Supplementary Fig. $2 \mathrm{e}$ ) prior to addition of ${ }^{3} \mathrm{H}-25 \mathrm{HC}$. ${ }^{3} \mathrm{H}-25 \mathrm{HC}$ bound to the av 33 integrin protein was then evaluated. Our result indicated a specific interaction of $25 \mathrm{HC}$ with site-II of the integrin molecule as there was a significant loss $(>60 \%)$ of $25 \mathrm{HC}$ binding to $\alpha v \beta 3$ integrin in the presence of fractalkine-CD protein (Fig. 2i). This result demonstrated specific interaction of $25 \mathrm{HC}$ with integrin molecules.

Molecular modeling of $25 \mathrm{HC}-\alpha v \beta 3$ integrin interaction. Next, we performed molecular docking and MD simulations to interrogate the potential interactions and outside-in activation mechanism of $25 \mathrm{HC}$ with integrins using av $\beta 3$ integrin-25HC complex as a model. MD simulation is a useful tool for understanding biological function-based conformational dynamics as it provides high-resolution details of spatial arrangement of atoms in a system over time. We investigated two possible binding sites for $25 \mathrm{HC}$. The first was at site I, the RGD-binding site (Fig. 3a) and the second site (site-II) was the binding site for fractalkine (FKN) and phospholipase A2 (sPLA-IIA) (Fig. 3a and Supplementary Table 2$)^{35,36}$. We performed an induced fit docking protocol in which the relative positions of side chains of binding site residues were optimized at the final refinement stage. The subsequent $\mathrm{MD}$ simulation revealed that $25 \mathrm{HC}$ did not bind to the RGD-binding site (Supplementary Movie 1). Rather, binding was favored at site-II (Supplementary Movie 2). The best pose from the docking simulation (Fig. 3b) was selected based on the number and strength of $\mathrm{H}$-bond interactions (H-bond distance and angle), number of hydrophobic interactions, and buried surface area.

The ligand bound protein-25HC complex and the unbound protein were subjected to $200 \mathrm{~ns} \mathrm{MD}$ simulations each and the resulting trajectories were analyzed for conformational changes in av $\beta 3$ integrin upon $25 \mathrm{HC}$ binding. We focused on three $\mathrm{H}$-bonds (Fig. 3b) observed between 3 - and $25-\mathrm{OH}$ groups of $25 \mathrm{HC}$ and binding site residues at the interface between $\beta \mathrm{I}$ and $\beta$-propeller domains. The residue A263 from the $\beta$ I domain, situated at the buried interface and close to the specificity-determining loop (SDL) of the molecule, makes a strong H-bond between its backbone carbonyl oxygen and the $25-\mathrm{OH}$ group of $25 \mathrm{HC}$. This $\mathrm{H}$-bond had just over $50 \%$ occupancy and was observed to have geometries (average distance $\sim 2.8 \AA$ and angle $\sim 165^{\circ}$ ) that are indicative of strong $\mathrm{H}$-bond interactions (Fig. $3 \mathrm{c}, \mathrm{d}$ ). At $\sim 110 \mathrm{~ns}$, the ligand readjusts its orientation (Fig. $3 c, d$ ) and move a little upward towards S162 of the SDL. Owing to this reorientation, the $\mathrm{H}$-bond with A263 weakens but seems to continue as electrostatic interactions. The 25-OH group was also pinned by $\mathrm{S} 162$ from the SDL. The backbone amide $-\mathrm{NH}$ and sidechain $-\mathrm{OH}$ groups of this residue intermittently flipped sides and consistently engaged in $\mathrm{H}$-bond interactions with optimal geometries (distance $\sim 2.9-3.0 \AA$ and angle $\sim 158-160^{\circ}$ ) during the entire simulation with occupancy of $>95 \%$. Thus, conformational flipping of Ser162 generated sufficient stimulus to trigger SDL movement, leading to permanent conformational change (discussed below). This event occurred approximately at $30 \mathrm{~ns}$ of the $200 \mathrm{~ns}$ simulation. During the entire $200 \mathrm{~ns}$ simulation, the bonding partners engaged in the
$\mathrm{H}$-bond interaction showed random oscillation from the ideal geometries, indicating the bond dynamics (Fig. 3c, d and Supplementary Movie 2). The 3-OH group of the ligand engages in moderately strong electrostatic interaction with $-\mathrm{OH}$ sidechain of S399 throughout the entire $200 \mathrm{~ns}$ simulation often satisfying the criteria of H-bonds (Fig. 3c, d and Supplementary Movie 2). In addition, 25HC made several nonpolar interactions with residues at the interface of the $\beta$-propeller and $\beta I$ domains (Y18, K42, W93, L111, and M400 of the $\beta$-propeller domain and V161, M165, A263, I265, Q267, V266, T285, and T286 of the $\beta \mathrm{I}$ domain).

The stable and lasting interactions of $25 \mathrm{HC}$ at the integrinbinding site [root-mean-square deviation (RMSD) $<1$ Å, Supplementary Fig. 3e] were partly due to the amount of hydrophobic surface buried upon ligand binding. It is well documented that large gains in binding free energy of several $\mathrm{kcal} / \mathrm{mol}$ per heavy atom (non-hydrogen) can be obtained when a lipophilic protein pocket is optimally occupied by nonpolar ligand atoms $\mathrm{s}^{37}$. It is noteworthy to mention that the aryl rings of W93 and Y18 from the $\beta$-propeller domain also engaged in Alkyl-Aryl interactions with the $-\mathrm{CH} 3$ groups of $25 \mathrm{HC}$. The stable van der Waal (steric) interactions between these two interacting molecules can be qualitatively observed by the distance (Supplementary Fig. 3f) measured between the center of mass (COM) of binding site residues and that of $25 \mathrm{HC}$ molecule.

The SDL in the $\beta$ I domain of the $\beta 3$ subunit is formed by the residue sequence K156-G189 and has been shown to be critical for ligand binding at the 'RGD"-binding site $32,38,39$. In addition, the SDL determines a-subunit association specificity and the conformation of the SDL is dependent on the associating $\alpha$ subunit $^{40}$. In our 200 ns long MD simulation run, we observed that the H-bond network between K125, Y122, and T182 of SDL was disrupted by $25 \mathrm{HC}$ binding to av $\beta 3$ integrin. This was not observed in the unbound state simulation. The disruption mainly occurred between T182-Y122 H-bond that connects the loop to the a1-helix (Fig. 3f). It is important to note that this disruption arose at exactly the same time $(\sim 30-40 \mathrm{~ns})$ when the SDL underwent a significant conformational change (RMSD of $>6 \AA$ ) (Fig. $3 \mathrm{e}$ and Supplementary Fig. 3a, c). The conformational change observed in the SDL is also caused by the disruption of notable electrostatic interaction between Q120 of the $\beta$-propeller and P169 of the SDL (Fig. 3h, i), which remains stable in the unbound protein. Thus, the 25HC-mediated change in this region could potentially alter the ligand-binding ability at the RGDbinding site (i.e., site I), as well as at binding sites on both the SDL and $\beta$-propeller (Fig. 3b, f). The movement of the SDL (Fig. 3f and Supplementary Fig. 3a, c) resulted in notable changes in the 2 - and 3-coils of the propeller blades that interact with the $\beta \mathrm{I}$ domain. The overall change in the surface property resulted in an increase of $>200 \AA^{2}$ in the solvent accessible surface area (SASA) of these loop regions combined (Supplementary Fig. 3c). Additional essential dynamics analyses quantifying global conformational changes, as well as correlated motions of various subunits are presented as RMSD (Fig. 3e), RMSF (Supplementary Fig. 3a), correlation matrix (Fig. 3g), SASA (Supplementary Fig. 3b) and porcupine plot (Supplementary Fig. 3d). The detailed description of these analyses are provided as Supplementary Note 1.

Correlated motions in biological molecules are essential for their function, for example, during ligand-mediated allosteric signal transduction ${ }^{41}$. The correlated and anti-correlated motions among various domains of the integrin $\alpha v \beta 3$ were visualized as porcupine plot and heat maps generated using Visual Molecular Dynamics (VMD 1.9.2) and Lattice package in R (version 3.3.1) software, respectively (Fig. 3g, Supplementary Fig. 3d, and Supplementary Movie 3). The porcupine plot revealed an 
a
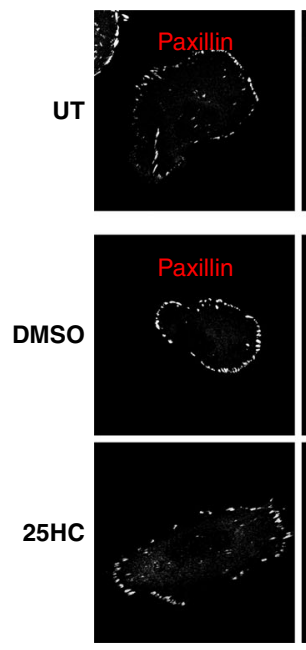

A549
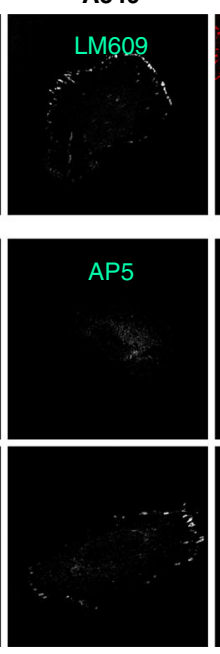
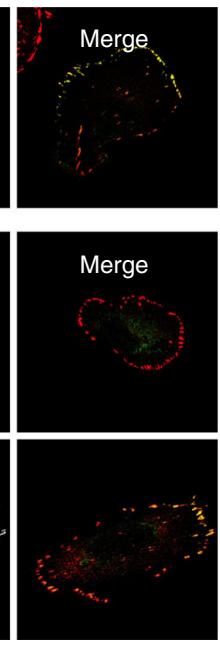
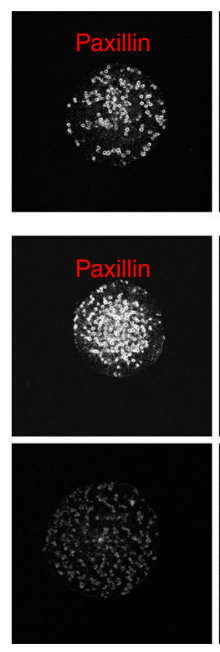

THP-1
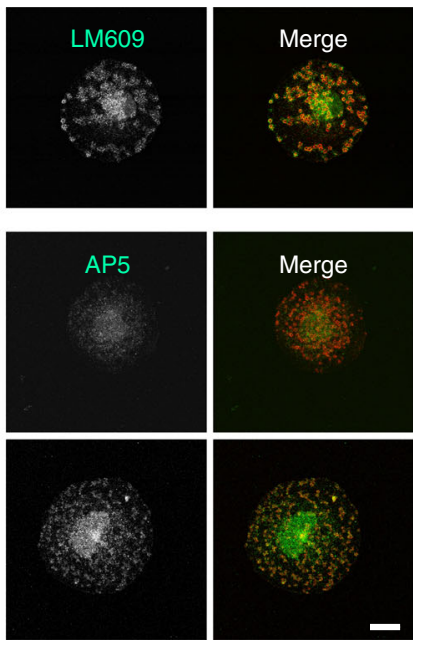
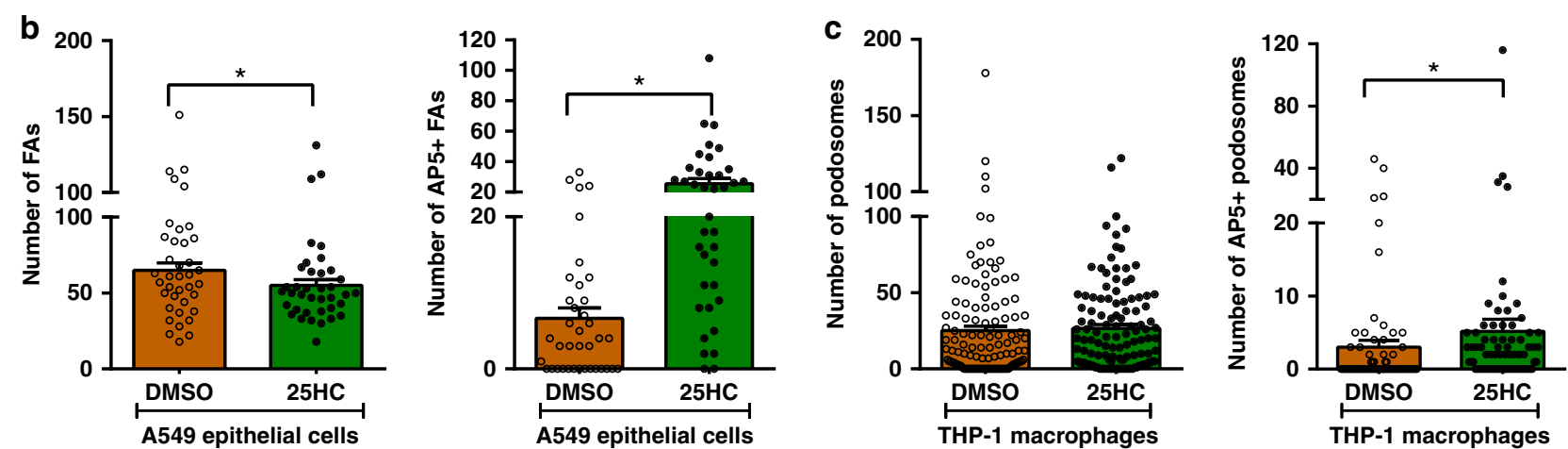

Fig. $425 \mathrm{HC}$ activates $\alpha v \beta 3$ integrin in epithelial cell focal adhesions and macrophage podosomes. a Human lung epithelial cells (A549 cells) or differentiated THP-1 macrophages were subjected to various treatments and immunostained as indicated. In untreated (UT) A549 and THP-1 cells (first row), $\alpha v \beta 3$ integrin, immunostained using the antibody LM609, was present in paxillin-positive focal adhesions and podosomes, respectively. In contrast, active $\alpha v \beta 3$ integrin staining, indicated using the antibody AP5 (second and third row), was found almost exclusively in cells treated for $2 \mathrm{~h}$ with $0.5 \mu \mathrm{M}$ $25 \mathrm{HC}$ compared with DMSO-treated controls. Merged images show the co-localization of $\alpha v \beta 3$ integrin (total or activated) with focal adhesions/ podosomes. Bar, $10 \mu \mathrm{m}$. b Quantification of the number of focal adhesions (FAs) and AP5+ FAs in A549 cells (three experiments, $>12$ cells per experiment; $n \geq 30$ ). c Quantification of the number of podosomes and AP5+ podosomes in THP-1 cells (three experiments, 25 cells per experiment; $n \geq 70$ ). Two- and One-tailed Wilcoxon rank-sum tests were performed to evaluate differences between total and AP5+ FA/podosome counts, respectively. Graphs depict mean \pm SEM. * $p \leq 0.05$

interesting pattern of dynamics between the head and leg regions of the $\alpha v \beta 3$ integrin, in which the ligand-binding site containing the $\beta$-propeller and $\beta \mathrm{I}$ domains made inward motion toward the calf-2 domain of the leg region, possibly transmitting the activation signal directly to the leg region attached to the transmembrane tail. The heat maps of correlation matrices depict the conformational and dynamic difference between unbound and 25HC-bound states (Fig. 3g). The increased anti-correlated motions correspond to the observed conformational change at the interface between $\beta$-propeller and SDL region of $\beta \mathrm{I}$ (dotted regions in the map in Fig. $3 \mathrm{~g}$ ), as well as notable conformational changes of the $\alpha 1$ and $\alpha 7$ helices (Fig. 3e and Supplementary Fig. 3a) in the molecule.

Binding of RGD motif-containing ligand mimetic compounds to site $I$ is mechanically coupled to tertiary changes in the $\beta \mathrm{A}$ domain, involving inward movement of the N-terminal $\alpha 1$ helix toward the MIDAS, forcing reorganization of the loop between the C-terminal F strand and $\alpha 7$ helix, a one-turn displacement of helix $a 7$ and a hybrid domain swing out ${ }^{42}$. We carefully monitored any conformational changes in these regions of site I, upon $25 \mathrm{HC}$ binding to site-II. The root-mean-square fluctuations (RMSF), RMSD, and SASA calculations revealed notable movement of the a1-helix (RMSD change of $\sim 4.2 \AA$ and SASA change of 300 to $500 \AA$ for the entire $\beta I$ domain), which stabilized after an $\sim 40$ ns simulation (Fig. 3e and Supplementary Fig. 3a, b). The angles between hybrid and $\beta I$ domains, as well as between $\beta$ propeller and calf-2 domains were calculated between their respective centers of mass. The angle between the hybrid and $\beta \mathrm{I}$ domain showed a very moderate $\sim 2^{\circ}$ increase for the first $30 \mathrm{~ns}$ of simulation time, which eventually dropped to its original angle of $\sim 82^{\circ}$. In contrast, unbound integrin exhibited a relatively larger increase $\left(\sim 6^{\circ}\right)$ in the angle, which eventually dropped to the original angle as well. The angle between $\beta$-propeller and calf- 2 domains exhibited notable movement in opposite directions, resulting in a decrease of angle, from $\sim 46^{\circ}$ to $\sim 42^{\circ}$ between the domains (Supplementary Fig. 3d and Supplementary Movie 3).

Our MD study indicated that $25 \mathrm{HC}$ binds to site-II of $\alpha \mathrm{v} \beta 3$ integrin and is consistent with both our SPR analyses (Fig. 2h) and competitive binding assay (Fig. 2i). Indeed, based on our data, we postulate that binding of $25 \mathrm{HC}$ to site-II of $\alpha v \beta 3$ integrin may directly trigger integrin signaling as observed previously for ligands that bind to site-II. Furthermore, binding of $25 \mathrm{HC}$ to siteII of $a v \beta 3$ integrin generated significant conformational changes at the $\beta \mathrm{I}$ domain, mainly altering the shape of the SDL, resulting 


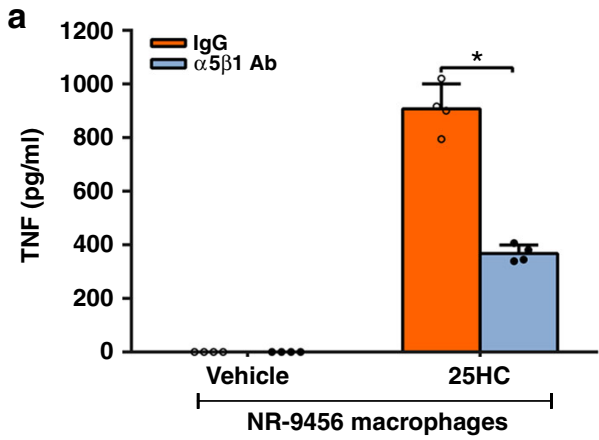

d
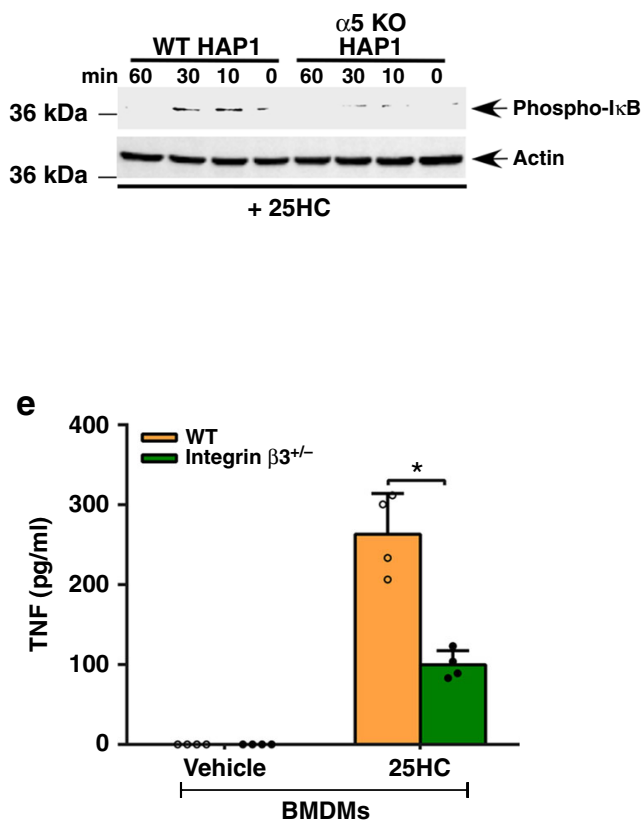
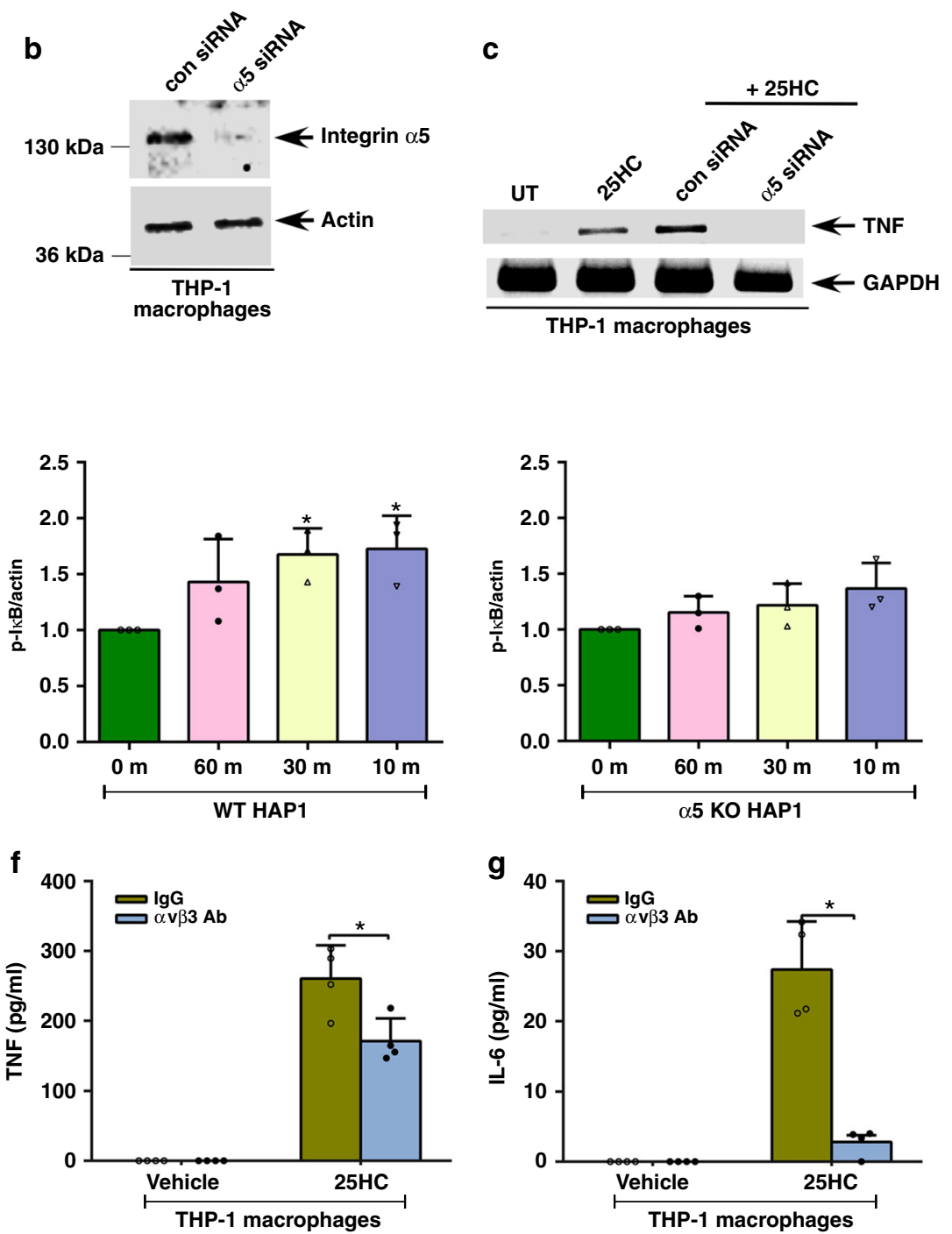

Fig. $5 \alpha 5 \beta 1$ and $\alpha v \beta 3$ integrins regulate $25 \mathrm{HC}$-mediated proinflammatory response. $\mathbf{a}, \mathbf{c}-\mathbf{g} \alpha 5 \beta 1$ and $\alpha v \beta 3$ integrin-deficient cells were treated with $50 \mu \mathrm{M}$ $25 \mathrm{HC}$ for $8 \mathrm{~h}$ to evaluate NFKB activation and proinflammatory response. a TNF secretion from 25HC-treated NR-9456 macrophages in the presence of either control IgG or $\alpha 5 \beta 1$ integrin blocking antibody (Ab). b Western blot analyses of $\alpha 5$ integrin protein expression in THP- 1 cells transfected with either control siRNA (con siRNA) or $\alpha 5$ integrin-specific siRNA ( $\alpha 5$ siRNA). c RT-PCR analyses of TNF expression in $25 \mathrm{HC}$-treated THP-1 cells transfected with either control siRNA (con siRNA) or $\alpha 5$ integrin-specific siRNA ( $\alpha 5$ siRNA). d Western blot and densitometric analyses of phospho-I $\mathrm{kB}$ status in $25 \mathrm{HC}$ treated wild-type (WT) and $\alpha 5$ integrin knockout (KO) HAP1 cells. e TNF secretion from $25 \mathrm{HC}$-treated WT and $\beta 3$ integrin-deficient ( $\beta 3^{+/}-$cells) BMDMs. $\mathbf{f}, \mathbf{g}$ TNF (f) and IL-6 (g) secretion from 25HC-treated THP-1 macrophages in the presence of either control lgG or $\alpha v \beta 3$ integrin blocking antibody (Ab). RT-PCR images are representative from two independent experiments. The ELISA values (mean \pm standard deviation) are representative from two or three independent experiments $(n=4)$. ${ }^{\star} p \leq 0.05$ using a Student's $t$-test. The densitometric quantification values for phospho- $\mid \kappa B$ ( $p$ - $\mid \kappa B$ ) immunoblot represent the ratio of phospho-IкB:actin and the fold-induction was calculated after normalizing with the control 0 min group. The densitometric values represent the mean \pm standard deviation from three independent studies. ${ }^{*} p \leq 0.05$ using a Student's $t$-test

in corresponding changes at the interacting surface of $\beta$-propeller domain. The observed changes at both the SDL and coils/turns of the $\beta$-propeller could, therefore, result in functional alteration in ligand-binding affinity at the 'RGD"-binding site (i.e., site I), leading to binding of $\alpha v \beta 3$ integrin-specific extracellular matrix (ECM) ligands to site I. Further MD stimulation and analyses also revealed binding of $25 \mathrm{HC}$ to the site-II of a5 31 integrin (Supplementary Notes).

25HC activates $\alpha \mathrm{v} \beta 3$ integrin at matrix adhesion sites. Our MD studies indicated that $25 \mathrm{HC}$ binding to av $\beta 3$ integrin resulted in changes in integrin conformation. As the ability of integrins to signal depends on their conformation, we tested the hypothesis that the binding of $25 \mathrm{HC}$ to av $\beta 3$ integrin affects its activity. Initially, we used the human epithelial cell line A549 as A549 cells express $a v \beta 3$ integrin in their focal adhesions (FAs) (Fig. 4a, b). In addition, we chose these cells due to the availability of humanreactive antibody probes, including those that recognize integrin subunits in an active conformation. 25HC treatment of A549 cells induced only a small, $15 \%$, decrease in the number of paxillinpositive FAs (Fig. 4b). However, when we immunostained control and 25HC-treated A549 cells with antibodies targeting paxillin and active $\alpha v \beta 3$ integrin using the antibody AP5, we observed negligible levels of active $\alpha v \beta 3$ integrin in the FAs of untreated cells but a dramatic and significant increase in active av $\beta 3$ integrin was observed following $25 \mathrm{HC}$ treatment (Fig. $4 \mathrm{a}, \mathrm{b}$ ). It should be noted that treatment of cells with $25 \mathrm{HC}$ did not alter 

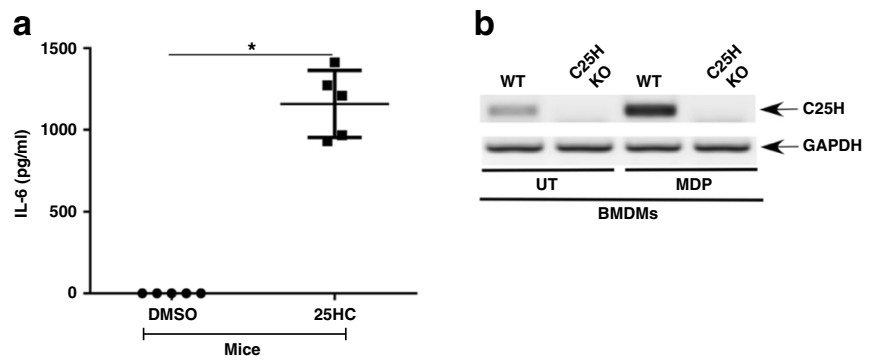
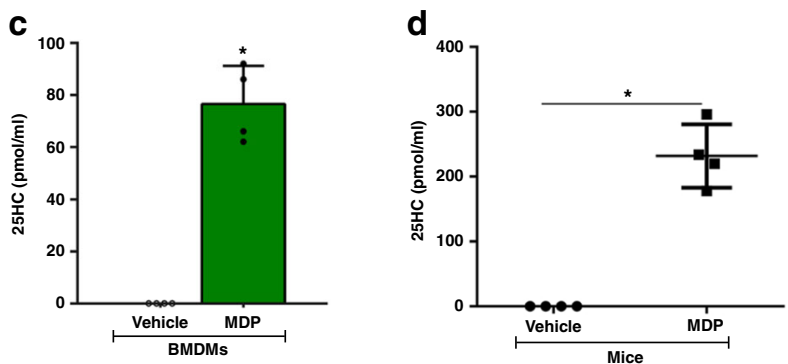

f

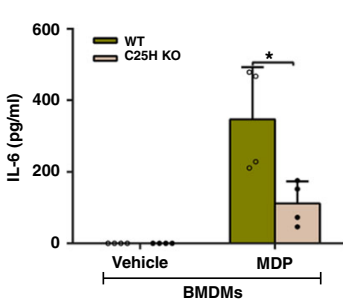

h

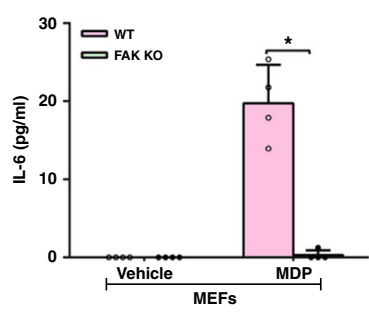

I

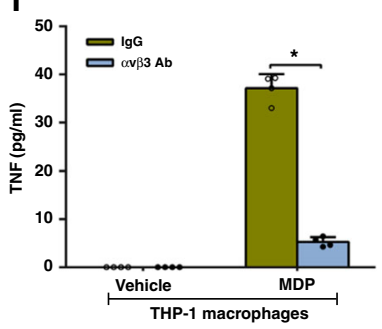

g
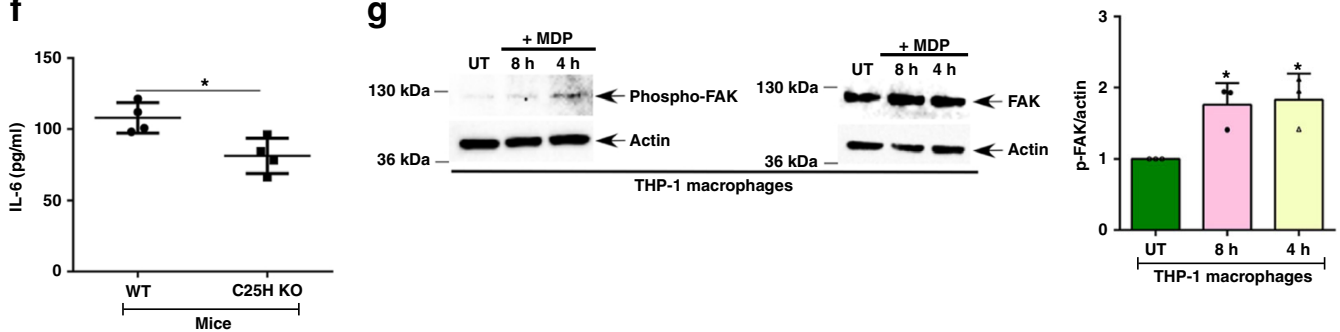

j
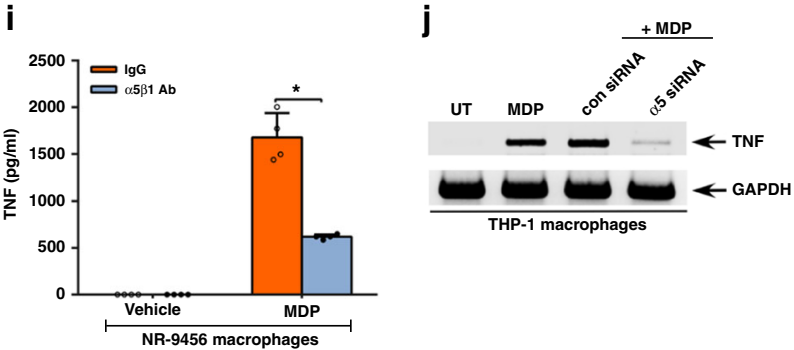

k

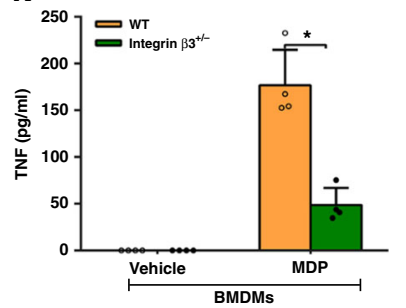

m

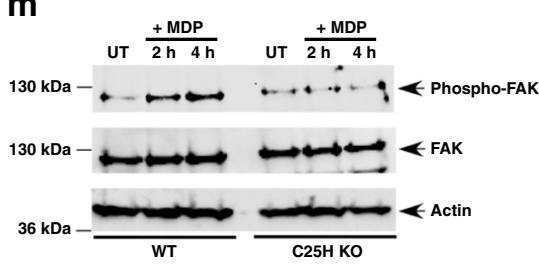

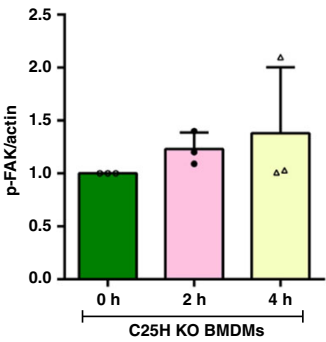

Fig. 6 The 25HC-integrin-FAK signaling network is required for optimal Nod2 response. a IL-6 in serum of mice injected (via intraperitoneal route) with $25 \mathrm{HC}(50 \mathrm{mg} / \mathrm{kg} ; 4 \mathrm{~h})(n=5) . \mathbf{b}, \mathbf{c}, \mathbf{e}, \mathbf{g}-\mathbf{m}$ Cells were treated with $25 \mu \mathrm{g} / \mathrm{ml}$ of MDP for $8 \mathrm{~h}$ and $\mathbf{d}, \mathbf{f}$ mice were injected intraperitoneally with $20 \mathrm{mg} / \mathrm{kg}$ of MDP for $4 \mathrm{~h}$. $\mathrm{C} 25 \mathrm{H}$ expression, $25 \mathrm{HC}$ production, FAK activation, and proinflammatory response were assessed. $\mathbf{b} \mathrm{RT}-\mathrm{PCR}$ analyses of $\mathrm{C} 25 \mathrm{H}$ expression in MDP-treated wild-type (WT) and C25H knockout (KO) BMDMs. c $25 \mathrm{HC}$ levels in the medium supernatant of MDP-treated BMDMs. d 25HC levels in the serum of WT mice treated with MDP $(n=4)$. e IL-6 secretion from WT and C25H KO BMDMs treated with MDP. f IL-6 levels in the serum of WT and $\mathrm{C} 25 \mathrm{H} \mathrm{KO}$ mice treated with MDP $(n=4)$. $\mathbf{g}$ Western blot and densitometric analyses of FAK activation (phospho-FAK, Tyr397) status in MDP-treated THP-1 macrophages. h IL-6 production from MDP-treated WT and FAK KO MEFs (mouse embryo fibroblasts). i IL-6 secretion from MDP-treated NR-9456 macrophages in the presence of either control lgG or $\alpha 5 \beta 1$ integrin blocking antibody (Ab). $\mathbf{j}$ RT-PCR analyses of TNF expression in MDP-treated THP1 cells transfected with either control siRNA (con siRNA) or $\alpha 5$ integrin-specific siRNA ( $\alpha 5$ siRNA). $\mathbf{k}$ TNF secretion from MDP-treated WT and $\beta 3$ integrindeficient ( $\beta 3^{+/-}$cells) BMDMs. I TNF secretion from MDP-treated THP-1 macrophages in the presence of either control lgG or $\alpha v \beta 3$ integrin blocking antibody. $\mathbf{m}$ Western blot and densitometric analyses of FAK activation (phospho-FAK, Tyr925) status in MDP-treated WT and C25H KO BMDM. RT-PCR images are representative from two independent experiments. The ELISA values (mean \pm standard deviation) are representative from two or three independent experiments $(n=4) .{ }^{*} p \leq 0.05$ using a Student's $t$-test. The densitometric quantification values for phospho-FAK ( $p$-FAK) immunoblot represent the ratio of phospho-FAK:actin and the fold-induction was calculated after normalizing with the control untreated (UT) group. The densitometric values represent the mean \pm standard deviation from three independent studies. ${ }^{\star} p \leq 0.05$ using a Student's $t$-test

the internalization rate of cell surface $\alpha v \beta 3$ integrin. The internalization rate of av $\beta 3$ integrin was similar in DMSO versus 25HC-treated cells (Supplementary Fig. 4a).

$25 \mathrm{HC}$ has been demonstrated to be an effector of innate immunity in macrophages ${ }^{26}$. Thus, we next assayed the impact of $25 \mathrm{HC}$ on av 33 integrin localization in human THP-1 monocytic cells that were induced to differentiate into a macrophage-like phenotype by phorbol 12-myristate 13-acetate (PMA). av $\beta 3$ integrin co-localized with paxillin in the podosomes of PMAdifferentiated THP-1 cells (Fig. 4a). Although 25HC treatment did not affect the number of podosomes in THP-1 cells, substantially more activated $\alpha v \beta 3$ integrin was incorporated into the podosomes of $25 \mathrm{HC}$-treated cells compared with their vehicle-treated counterparts (Fig. $4 a, c$ ). 


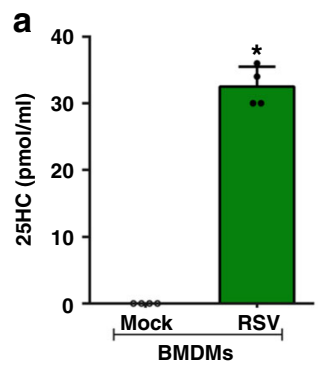

d

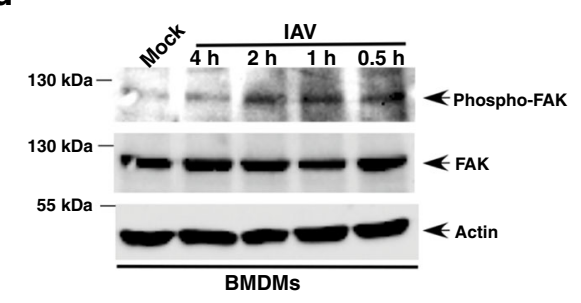

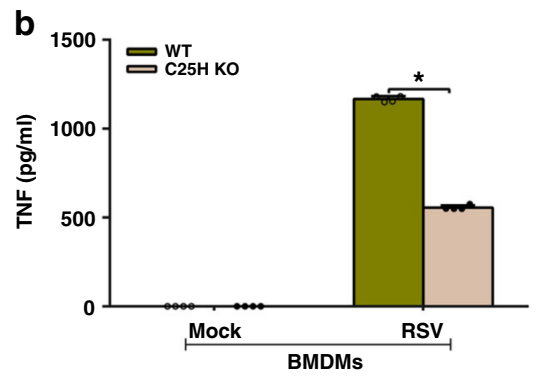

c

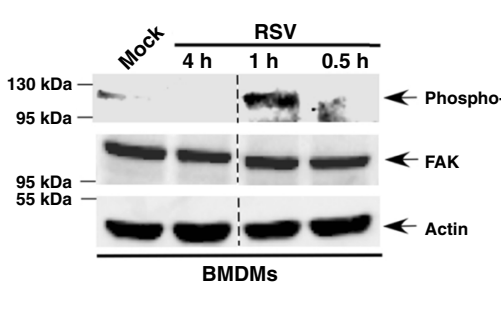

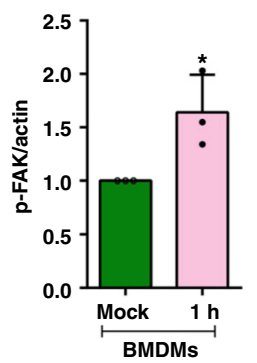

e

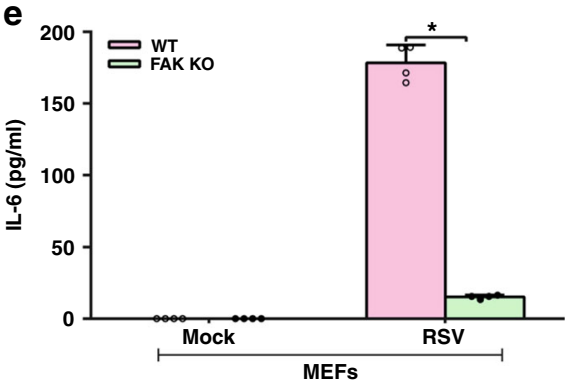

f
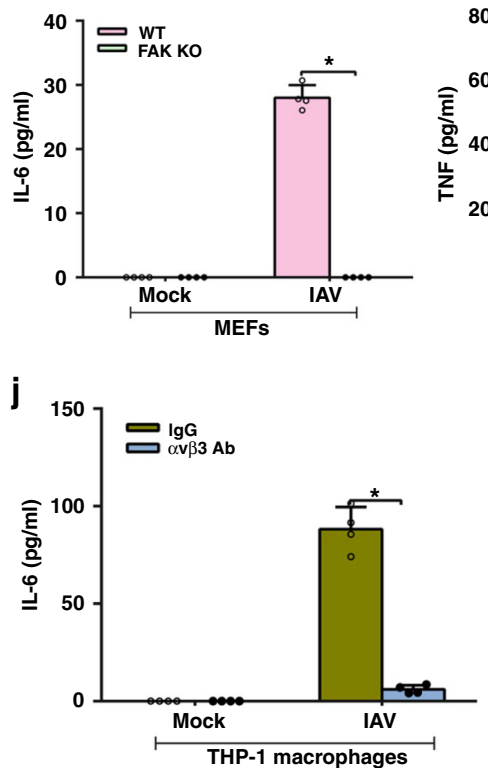

g

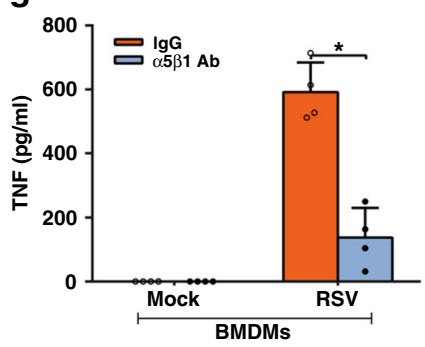

h

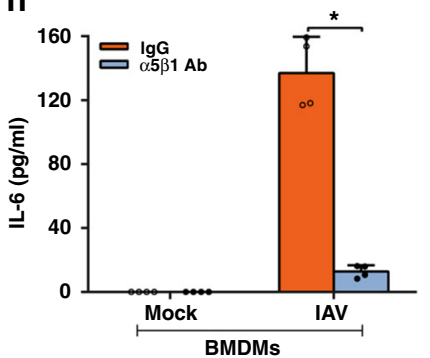

i

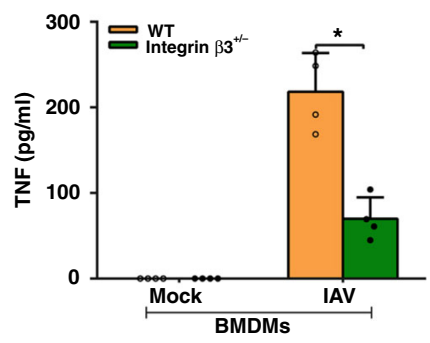

$\mathbf{k}$

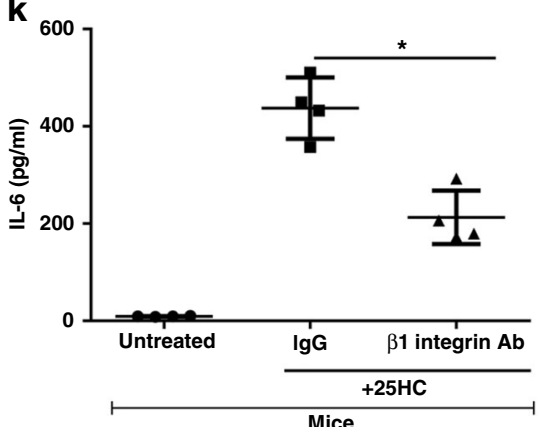

I

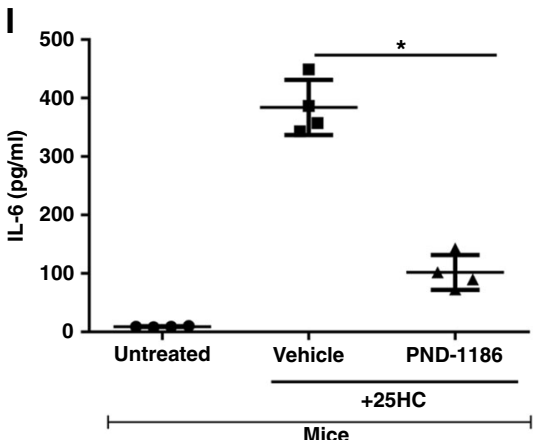

Fig. 7 The $25 \mathrm{HC}$-integrin-FAK signaling network regulates proinflammatory response during virus infection. a $25 \mathrm{HC}$ levels in the medium supernatant of BMDMs infected with human respiratory syncytial virus (RSV). b TNF production from wild-type (WT) and C25H knockout (KO) BMDMs infected with RSV. c Western blot and densitometric analyses of FAK activation (phospho-FAK, Tyr925) status in RSV-infected BMDMs. d Western blot and densitometric analyses of FAK activation (phospho-FAK, Tyr925) status in influenza A virus (IAV)-infected BMDMs. e IL-6 production from RSV-infected WT and FAK KO MEFs. $\mathbf{f I L - 6}$ production from IAV-infected WT and FAK KO MEFs. $\mathbf{g}$ TNF production from RSV-infected BMDMs in the presence of either control IgG or $\alpha 5 \beta 1$ integrin blocking antibody (Ab). $\mathbf{h}$ IL-6 production from IAV-infected BMDMs in the presence of either control IgG or $\alpha 5 \beta 1$ integrin blocking antibody. i TNF secretion from IAV-infected WT and $\beta 3$ integrin-deficient ( $\beta 3^{+/-}$cells) BMDMs. $\mathbf{j}$ IL- 6 secretion from IAV-infected THP- 1 cells in the presence of either control IgG or $\alpha v \beta 3$ integrin blocking antibody. $\mathbf{k}$ IL- 6 in the lungs of mice injected (via intratracheal or I.T route) with $25 \mathrm{HC}$ $(5 \mathrm{mg} / \mathrm{kg} ; 6 \mathrm{~h})$ in the presence of either IgG or $\beta 1$ integrin blocking antibody (Ab) administered to the mice via I.T route $(n=4)$. I IL-6 in the lungs of mice injected (via I.T route) with $25 \mathrm{HC}(5 \mathrm{mg} / \mathrm{kg} ; 6 \mathrm{~h})$ in the presence of either vehicle (control) or FAK inhibitor (PND-1186) administered to the mice via I.T route $(n=4)$. The ELISA values (mean \pm standard deviation) are representative from two or three independent experiments $(n=4)$. ${ }^{\star} p \leq 0.05$ using a Student's $t$-test. The densitometric quantification values for phospho-FAK ( $p-F A K$ ) immunoblot represent the ratio of phospho-FAK:actin and the foldinduction was calculated after normalizing with the control mock-infected group. The densitometric values represent the mean \pm standard deviation from three independent studies. ${ }^{\star} p \leq 0.05$ using a Student's $t$-test 
As FAs and podosomes are involved in motility, we suspected that the activation of $\alpha v \beta 3$ integrin in these structures would affect cell migration. However, $25 \mathrm{HC}$ treatment did not have a substantial impact on speed or directed migration (processivity) (Supplementary Fig. 4b, c). Rather, the consequences of 25HCmediated $\alpha v \beta 3$ integrin and FAK activation in FAs and podosomes may be restricted to the signaling properties of these structures, a possibility we evaluated next.

25HC triggers integrin-dependent proinflammatory response. As $25 \mathrm{HC}$ interacted with both $\alpha 5 \beta 1$ and $\alpha v \beta 3$ integrin complexes and activated FAK (Figs. 1 and 2), we assayed whether these effects regulated the proinflammatory response triggered by $25 \mathrm{HC}$. Inhibiting cell surface $\alpha 5 \beta 1$ integrin with integrin blocking antibody diminished TNF production from $25 \mathrm{HC}$-treated primary mouse macrophages by $60 \%$ compared to control, IgGtreated cells (Fig. 5a). To validate this result, we silenced a5 integrin expression in THP-1 cells using small-interfering RNA (siRNA; Fig. 5b and Supplementary Fig. 5a). Compared with controls, these cells exhibited reduced expression of TNF (Fig. 5c) and IL-6 (Supplementary Fig. 5b) following 25HC treatment. Based on these results we predicted that lack of $\alpha 5$ integrin would abrogate NFkB activation by $25 \mathrm{HC}$. To evaluate NFkB status, we used a5 integrin knockout (KO) human haploid (HAP1) cells ${ }^{43}$, generated by CRISPR-Cas9 technology (Supplementary Fig. 5c). Indeed, we observed reduced $\mathrm{NF \kappa B}$ activation [i.e., diminished

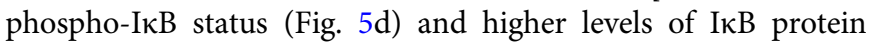
(Supplementary Fig. 5d)] in 25HC-treated a5 integrin $\mathrm{KO}$ HAP1 cells compared to wild-type (WT) HAP1 cells. Densito-

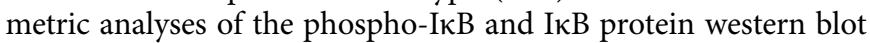
data revealed significant induction of $\mathrm{NF \kappa B}$ in $25 \mathrm{HC}$-treated WT cells, but not in a5 integrin $\mathrm{KO}$ cells (Fig. 5d and Supplementary Fig. 5d).

To further confirm our result we next evaluated the proinflammatory response in 25HC-treated wild-type (WT) and $\beta 3$ integrin-deficient ( $\beta 3$ integrin heterozygous $\beta 3^{+/-}$mice) BMDMs. TNF production by $\beta 3$ integrin-deficient BMDMs treated with $25 \mathrm{HC}$ was reduced by $62 \%$ compared to their WT counterparts (Fig. 5e). This result was further validated by treating human THP-1 macrophages with the human av 33 integrin blocking antibody LM609. LM609 reduced 25HCinduced production of TNF and IL- 6 by $35 \%$ and $90 \%$, respectively (Fig. 5f, g).

25HC-integrin-FAK amplifies proinflammatory response. To examine whether extracellular $25 \mathrm{HC}$ can trigger proinflammatory response in mice, we administered (via intraperitoneal route) $25 \mathrm{HC}$ to $\mathrm{C} 25 \mathrm{H} \mathrm{KO}$ mice, as they do not produce any $25 \mathrm{HC}$ and the observed response will be entirely due to exogenously added 25HC. 25HC-treated mice exhibited a robust and systemic proinflammatory response as evidenced by detection of IL- 6 in their serum (Fig. 6a). This suggested to us that the $25 \mathrm{HC}$ integrin-FAK signaling network might regulate a proinflammatory response by facilitating the activation of PRRs, such as Nod2. Activation of Nod2 by muramyl dipeptide (MDP) led to a substantial increase in $\mathrm{C} 25 \mathrm{H}$ expression and $25 \mathrm{HC}$ production by macrophages in vitro (Fig. $6 \mathrm{~b}, \mathrm{c}$ ). MDP also triggered $25 \mathrm{HC}$ production in vivo (Fig. 6d). Furthermore, compared to WT cells, there was a significant inhibition in IL- 6 production (reduced by $70 \%$ ) in $\mathrm{C} 25 \mathrm{H}$ KO BMDMs following MDP treatment (Fig. 6e). The specificity of $25 \mathrm{HC}$ during this process was evident as exogenous addition of $25 \mathrm{HC}$ to $\mathrm{C} 25 \mathrm{H} \mathrm{KO}$ cells restored a proinflammatory response following MDP administration (Supplementary Fig. 6a). The in vivo role of $25 \mathrm{HC}$ during a Nod2-mediated response was established as serum IL-6 levels in
MDP-treated $\mathrm{C} 25 \mathrm{H} \mathrm{KO}$ mice were reduced 32\% compared to WT mice (Fig. 6f).

As $25 \mathrm{HC}$ activated integrin-FAK signaling, we next assessed the role of the integrin-FAK pathway during Nod2 activation. MDP treatment resulted in an activation of FAK (i.e., detection of phospho-FAK) in macrophages (Fig. 6g). Densitometric analyses of the phospho-FAK western blot data revealed significant induction of FAK following MDP treatment (Fig. 6g). Furthermore, lack of FAK expression led to a complete loss of an MDPinduced proinflammatory response, as we detected negligible levels of IL-6 in FAK KO cells (Fig. 6h). Consistent with the latter result, inhibiting FAK activity in MDP-treated macrophages also resulted in complete abrogation in TNF production (Supplementary Fig. 6b). IL-6 production was also significantly compromised following inhibition of FAK activity in MDP-treated macrophages (Supplementary Fig. 6c). It should be noted that MDP treatment did not result in a loss of viability of either FAK KO macrophages or macrophages treated with a FAK inhibitor (Supplementary Table 1).

To assess the role of integrins, we evaluated TNF production from MDP-treated primary mouse macrophages in the presence of $\alpha 5 \beta 1$ integrin blocking antibody. There was a reduction of $65 \%$ in TNF production in the antibody-treated cells compared to the control (Fig. 6i). These results were further validated by using $a 5$ integrin silenced macrophages (Fig. $5 \mathrm{~b}$ and Supplementary Fig. 6d). Compared to control cells, a5 integrin-silenced cells exhibited reduced TNF and IL- 6 expression following MDP treatment (Fig. 6j and Supplementary Fig. 6e). TNF and IL-6 production following MDP treatment of $\beta 3$ integrin-deficient primary BMDMs was also reduced compared to controls by $75 \%$ and $70 \%$, respectively (Fig. 6k and Supplementary Fig. 6f). This result was further validated in human macrophages. In cultures of human THP-1 macrophages treated with MDP, av 33 integrin blocking antibody incubation resulted in a dramatic reduction (reduced by $85 \%$ ) of TNF production compared to control IgGtreated cells (Fig. 61).

Finally, the role of $25 \mathrm{HC}$ in inducing integrin-FAK signaling during a Nod2-mediated innate response was established by evaluating FAK activation status in MDP-treated WT and $\mathrm{C} 25 \mathrm{H}$ KO BMDMs. While MDP triggered FAK activation (i.e., detection of phospho-FAK) in WT cells, such activation was lacking in MDP-treated C25H KO cells (Fig. 6m). Densitometric analyses of the phospho-FAK western blot data revealed significant induction of FAK in MDP-treated WT cells, but not in $\mathrm{C} 25 \mathrm{H} \mathrm{KO}$ cells (Fig. $6 \mathrm{~m}$ ). These results demonstrated that $25 \mathrm{HC}$ promotes activation of integrin-FAK signaling, thereby amplifying proinflammatory response during a Nod2-mediated innate immune response.

25HC-integrin-FAK pathway regulates viral response. Respiratory syncytial virus (RSV) and influenza A virus (IAV), two respiratory RNA viruses, activate Nod2 in macrophages, which, in turn, regulates a proinflammatory and innate immune response $^{14-17}$. To assess whether $25 \mathrm{HC}$-integrin-FAK signaling modulates a proinflammatory response during infection, we first assessed $\mathrm{C} 25 \mathrm{H}$ expression and $25 \mathrm{HC}$ production in cultures of RSV-infected macrophages. RSV induced $\mathrm{C} 25 \mathrm{H}$ expression (Supplementary Fig. 7a), which resulted in $25 \mathrm{HC}$ production (Fig. 7a). IAV also triggered $25 \mathrm{HC}$ production (Supplementary Fig. 7b). The importance of $25 \mathrm{HC}$ during RSV infection was demonstrated by the dampening of the proinflammatory response in RSV-infected $\mathrm{C} 25 \mathrm{H} \mathrm{KO}$ macrophages (Fig. 7b). Specifically, TNF and IL- 6 production were reduced by $52 \%$ and $44 \%$, respectively, following RSV infection of $\mathrm{C} 25 \mathrm{H} \mathrm{KO}$ macrophages (Fig. $7 \mathrm{~b}$ and Supplementary Fig. 7c). In accord with a 
previous report ${ }^{26}$, we also observed a diminished proinflammatory response following IAV infection of $\mathrm{C} 25 \mathrm{H} \mathrm{KO}$ BMDMs (Supplementary Fig. 7d). Thus, 25HC amplified the proinflammatory response following RSV and IAV infection.

Next, we examined the role of the integrin-FAK pathway during infection. Both IAV and RSV infection induced FAK activation in macrophages as phospho-FAK was detected in infected cells following western blot analyses (Fig. 7c, d). Densitometric analyses of the phospho-FAK western blot data revealed significant induction of FAK following infection (Fig. 7c, d). A role for FAK in regulating the proinflammatory response to RSV infection is apparent from the drastic reduction in IL-6 release from RSV-infected FAK KO cells (Fig. 7e). Similarly, TNF and IL-6 production was diminished in RSV-infected macrophages treated with a FAK inhibitor (Supplementary Fig. 7e, f). The loss of a proinflammatory response was also observed in IAV-infected FAK KO cells (Fig. 7f) and in macrophages treated with a FAK inhibitor (Supplementary Fig. 7g). Neither treatment condition nor infection status altered cell viability in these studies (Supplementary Table 1). Moreover, our results are not due to FAK regulating infectivity, as RSV and IAV viral infection was similar in WT and FAK KO cells (Supplementary Fig. 8a, b).

Next, we evaluated the role of $\alpha 5 \beta 1$ and $\alpha v \beta 3$ integrins during virus infection. TNF production of RSV-infected cells declined by $80 \%$ following incubation with $\alpha 5 \beta 1$ integrin blocking antibodies (Fig. 7g). Likewise, incubation of IAVinfected cells with a5 11 integrin blocking antibody resulted in a $90 \%$ reduction in IL-6 production (Fig. 7h). Furthermore, TNF production was reduced by $70 \%$ in $\beta 3$ integrin-deficient macrophages (BMDMs from $\beta 3^{+/-}$mice) following IAV infection compared to controls (Fig. 7i). This result was further validated in IAV-infected THP-1 human macrophages as antihuman av $\beta 3$ integrin blocking antibodies diminished IL-6 production in these cells by $95 \%$ (Fig. $7 \mathrm{j}$ ).

It has been suggested that $\mathrm{C} 25 \mathrm{H}$ possesses antiviral functions against various viruses ${ }^{44}$. A recent study showed that $\mathrm{C} 25 \mathrm{H}$ lacks in vivo antiviral activity against $\mathrm{IAV}^{26}$. In accord with this result, we did not observe any difference in RSV and IAV infectivity in WT versus $\mathrm{C} 25 \mathrm{H}$ KO BMDMs (Supplementary Fig. 8c, d). Taken together, the results of our study indicated an involvement of $25 \mathrm{HC}$-integrin-FAK signaling network in positively regulating proinflammatory response during RSV and IAV infection.

In order to demonstrate that $25 \mathrm{HC}$ confers a proinflammatory response via integrin-FAK pathway in an in vivo setting, we next used a physiologically relevant mouse model. Gold et al. ${ }^{26}$ demonstrated that IAV infection triggers induction of $\mathrm{C} 25 \mathrm{H}$. This result was confirmed as we detected $25 \mathrm{HC}$ in the lungs of IAV-infected mice (Supplementary Fig. 7h). In addition, studies performed by Gold et al. ${ }^{26}$ revealed that the absence of $25 \mathrm{HC}$ in $\mathrm{C} 25 \mathrm{H} \mathrm{KO}$ mice results in diminished proinflammatory response in IAV-infected mice ${ }^{26}$. To investigate the role of the integrinFAK pathway in 25HC-mediated activation of a proinflammatory response in a pathophysiological setting, mimicking IAV infection, we administered $25 \mathrm{HC}$ to the mouse airway either in the presence or absence of a $\beta 1$ integrin blocking antibody, previously employed to inhibit integrin activation in the mouse airway ${ }^{45}$, or the FAK inhibitor (PND-1186), which has been used in mice to block FAK activation ${ }^{46}$. This experimental design in a physiological setting is ideal to directly assess whether $25 \mathrm{HC}$ utilizes the integrin-FAK pathway to induce proinflammatory response in vivo. 25HC-dependent proinflammatory response in the lung was significantly diminished following administration of $\beta 1$ integrin blocking antibody (Fig. 7k) and FAK inhibitor (Fig. 7l). In summary, our results indicated that the integrin-FAK pathway plays an important physiological role in triggering 25HC-mediated response.

\section{Discussion}

The ability of integrins, clustered within matrix adhesion sites, to regulate signal transduction pathways that not only modulate cell adhesion and motility but also gene expression has been the subject of numerous studies ${ }^{1-6,9-12,27,28,47}$. Integrin-mediated signaling requires activation of the integrin molecule, a process which involves conformational changes resulting in enhanced ligand binding. Outside-in integrin signaling requires integrin interaction and activation by an extracellular ligand. This results in conformational changes in the cytoplasmic domains of the integrin heterodimer. The new conformation facilitates the recruitment and/or activation of signaling intermediates that bind to the cytoplasmic tails.

Apart from binding to ECM ligands, integrins can also interact with other non-conventional extracellular ligands such as adhesion molecules (e.g., ICAM, VCAM), phospholipase A2, and fractalkine $35,36,48$. These ligands appear to act as activators promoting ("priming") ligand interaction to induce the necessary conformational change in the cytoplasmic tail to trigger signaling $^{1-3,5}$.

To date non-protein ligands for integrins have not been described. As discussed above, only proteinaceous extracellular ligands for integrin have been described and a non-protein ligand for integrin has not been identified. Thus, the detection of a lipid as an integrin ligand is surprising. Moreover, we show that the oxysterol lipid 25HC directly interacts with a5 $\beta 1$ and $\alpha v \beta 3$ integrins to trigger integrin activation. Furthermore, our modeling analyses suggest that $25 \mathrm{HC}$, like fractalkine and sPLA2-IIA, interacts with $\alpha v \beta 3$ integrin via site-II in the extracellular domain of the $\beta 3$ integrin subunit ${ }^{35,36}$. Our modeling also indicates that this interaction affects the conformation of the specificitydetermining loop (SDL), located between residues Lys156Gly189 of the $\beta$ I domain of $\beta 3$ integrin. SDL determines binding to site I of numerous RGD motif-containing ligands, including fibrinogen, von Willebrand factor, vitronectin, and fibronectin $32,38,39,49,50$. We propose that $25 \mathrm{HC}$ binds to site-II, located in the globular heads of inactive $\alpha v \beta 3$ integrin, when the latter is in a bent conformation. This event could then "prime" activation of integrin signaling, a possibility supported by our observation that active av $\beta 3$ integrin is found in the podosomes of THP-1 cells only after $25 \mathrm{HC}$ treatment and $25 \mathrm{HC}$ promotes activation of $\alpha \mathrm{v} \beta 3$ integrin in FAs of A549 cells. However, in an alternative indirect mechanism, $25 \mathrm{HC}$ binding to site-II could induce conformational changes in the SDL, which may promote efficient "high-affinity" binding of RGD containing ligands (e.g., fibronectin, laminin etc.) in the site I ligand-binding pocket. Furthermore, such conformational change in SDL may also dictate "specificity" in terms of selective binding of RGD ligand to site I. Thus, we envision that both direct and indirect mechanisms of integrin activation by $25 \mathrm{HC}$ may either occur simultaneously or are temporally distinct. Furthermore, two mechanisms of integrin activation by $25 \mathrm{HC}$ may be utilized to maximize integrin signaling strength.

The data we have presented here regarding $25 \mathrm{HC}$ is an example of a lipid regulating integrin activation via direct binding. There was a single report in 1992 that an unsaturated acid or an isoprenoid acid acts as an activator of leukocyte integrins ${ }^{51}$. However, neither the nature of the lipid involved, nor its mechanism of action, were elucidated by the authors of the study ${ }^{51}$. Regardless, the ability of $25 \mathrm{HC}$ to modulate integrin activation adds to its already extensive list of activities of $25 \mathrm{HC}$ in modulating various cellular responses $26,44,52-55$.

As part of our efforts to elucidate the biological and functional roles of $25 \mathrm{HC}$-mediated integrin binding, we have uncovered a previously unknown mechanism that connects innate immunity to integrin signaling. During an innate immune response, the 


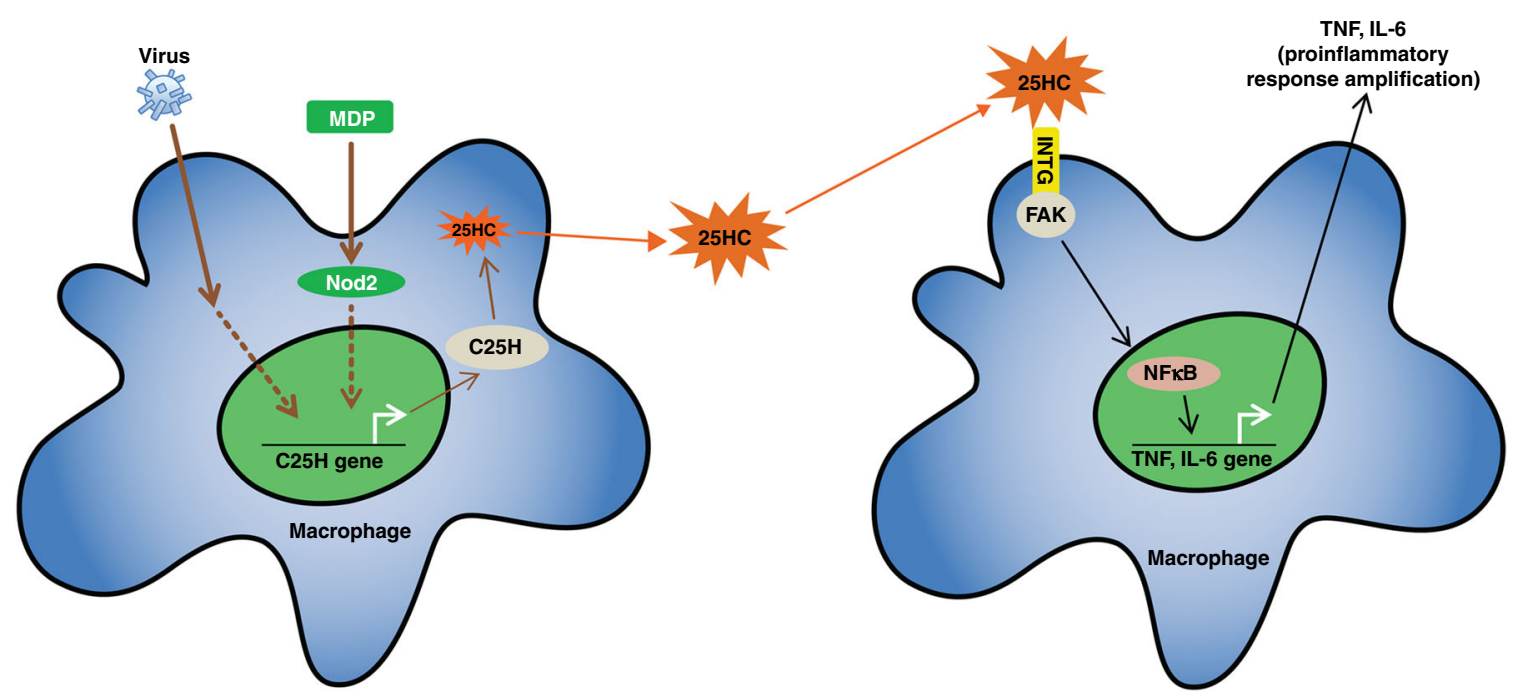

Fig. $8 \mathrm{~A}$ schematic model showing regulation of proinflammatory response by $25 \mathrm{HC}$-integrin-FAK signaling network. Nod2 activation and virus (RSV and IAV) infection triggers expression of $\mathrm{C} 25 \mathrm{H}$, which results in production of $25 \mathrm{HC}$. Extracellular $25 \mathrm{HC}$ activates integrin-FAK-NFKB signaling. Thus, $25 \mathrm{HC}$ links PRR (Nod2) pathway with integrin-FAK-NFkB signaling to confer optimal proinflammatory response following Nod2 activation and virus infection. INTG, integrin; FAK, focal adhesion kinase

PRR Nod2 senses unique pathogen-derived PAMPs and, as a consequence, induces NFKB and MAPK activation and a subsequent release of proinflammatory mediators.

Based on our study, we propose a "biphasic" model for Nod2 activation during viral infection (Fig. 8). We suggest that two "discrete", but "mutually inclusive" signals are required for optimal proinflammatory response following Nod 2 activation by PAMPs. First, a signal (first phase) occurring in "primed" cells promotes production of the first wave of proinflammatory mediators. PRR activation in these cells results in NFKB and MAPK activation and subsequent release of sub-optimal levels of proinflammatory mediators. During this process, $\mathrm{C} 25 \mathrm{H}$ is also induced in "primed" cells. $25 \mathrm{HC}$ generated due to enzymatic activity of $\mathrm{C} 25 \mathrm{H}$ is released to the extracellular milieu. Next, a signal (second phase) triggers production of a second wave of proinflammatory mediators. This is executed by the paracrine/ autocrine action of extracellular $25 \mathrm{HC}$. In the case of paracrine action, 25HC activates integrin-FAK signaling in "bystander" cells (i.e., the cells lacking activated PRR) to trigger proinflammatory response. We postulate that existence of two signals for triggering optimal PRR response during infection is an essential component of a host's "regulatory" mechanism to maintain proper "checks and balances" during inflammation. Thus, our studies have unfolded a role of the PRR-25HC-integrin-FAK-NFKB signaling network in amplifying inflammatory response.

In summary, our studies have led to identification of $25 \mathrm{HC}$ as an extracellular integrin "lipid" ligand involved in activation of integrin-FAK signaling to regulate innate immune response.

\section{Methods}

Viruses and cells. Influenza A $[\mathrm{A} / P R / 8 / 34(\mathrm{H} 1 \mathrm{~N} 1)]$ virus (IAV) and human respiratory syncytial virus (RSV A2 strain) were purified by centrifuging two times on discontinuous sucrose gradients ${ }^{14,56}$. Bone marrow-derived macrophages (BMDMs) were obtained from femurs and tibias of wild type (WT), C25H knockout (KO), NFkB p105 KO, and integrin $\beta 3^{+/-}$mice. BMDMs were cultured for 6-8 days and plated for experiments in 1640 RPMI, $10 \%$ FBS, $100 \mathrm{IU} / \mathrm{ml}$ Penicillin, $100 \mu \mathrm{g} / \mathrm{ml}$ Streptomycin (Gibco, Maryland, USA), and $20 \mathrm{ng} / \mathrm{ml} \mathrm{GM-CSF}$ (PeproTech, New Jersey, USA). NR-9456 macrophages (immortalized BMDMs) (a gift from Michael T. Berton, UT Health Science Center at San Antonio; Bei Resources, Virginia, USA; catalog no. NR-9456), RAW 264.7 macrophages (ATCC, Virginia, USA; catalog no. TIB-71), mouse embryo fibroblasts (WT and FAK KO MEFs) (ATCC; catalog no. CRL-2645 and CRL-2644) were maintained in complete DMEM containing 10\%
FBS, $100 \mathrm{IU} / \mathrm{ml}$ Penicillin, $100 \mu \mathrm{g} / \mathrm{ml}$ Streptomycin (Gibco). A549 cells (human lung epithelial cells) (ATCC; catalog no. CCL-185) were maintained in complete MEM containing 10\% FBS, $100 \mathrm{IU} / \mathrm{ml}$ Penicillin, $100 \mu \mathrm{g} / \mathrm{ml}$ Streptomycin and $4 \mathrm{mM}$ L-glutamine. The human monocyte cell line (THP-1) (ATCC; catalog no. TIB-202) were cultured in 1640 RPMI, 10\% FBS, $100 \mathrm{IU} / \mathrm{ml}$ Penicillin, $100 \mu \mathrm{g} / \mathrm{ml}$ Streptomycin, $1 \mathrm{mM}$ sodium pyruvate, $10 \mathrm{mM}$ HEPES, and $50 \mu \mathrm{M} \beta$-mercaptoethanol (Sigma Aldrich, Missouri, USA). THP-1 cells were differentiated by treatment with $100 \mathrm{nM}$ phorbol 12-myristate 13-acetate (PMA) (Sigma Aldrich). WT (catalog no. C631) and a5 integrin null (catalog no. HZGHC001085c001) human haploid (HAP1) cells, created using CRISPR-Cas9 technology were purchased from Horizon Discovery Inc (Vienna, Austria). HAP1 cells were maintained in IMDM, 10\% FBS, $100 \mathrm{IU} / \mathrm{ml}$ Penicillin, $100 \mu \mathrm{g} / \mathrm{ml}$ Streptomycin (Gibco). All cell lines used in the current study were tested for Mycoplasma using Universal Mycoplasma Detection kit (ATCC).

Cell treatment and infection. Cells were treated with freshly prepared 25HC (50 $\mu \mathrm{M}, 8 \mathrm{~h}$ ) (Steraloids, Rhode Island, USA) and the Nod2 activator muramyl dipeptide (MDP) $(25 \mu \mathrm{g} / \mathrm{ml}, 8 \mathrm{~h})$ (InvivoGen, California, USA). In some experiments, cells were pre-treated with either FAK inhibitor $(5 \mu \mathrm{M})$ (PF-431396; Sigma Aldrich) or NFkB inhibitor (10 $\mu \mathrm{M})$ (Bay-11-7082; InvivoGen) for $1 \mathrm{~h}$ or $30 \mathrm{~min}$, respectively. Subsequently, these cells were either treated with various agents (25HC and MDP) or infected with viruses (RSV and IAV). Cells were infected with purified IAV or RSV at the multiplicity of infection (MOI) of 1 . Virus adsorption was performed for $1.5 \mathrm{~h}\left(\right.$ at $\left.37^{\circ} \mathrm{C}\right)$ in serum-free, antibiotic-free OPTI-MEM medium (Gibco). Following adsorption, cells were washed twice with PBS and infection was continued for an additional $8 \mathrm{~h}$ or $16 \mathrm{~h}$ in the presence of serum containing complete medium with or without treatment. For in vitro experiments (i.e., experiments with cultured cells), standard biological replicates of $n=4$ were used.

Mice. Wild type (WT) (stock no. 000664), C25H knockout (KO) (stock no. 016263), NFkB p105 KO (stock no. 006097), and $\beta 3$ integrin-deficient ( $\beta 3$ integrin heterozygous $\beta 3^{+l-}$ mice) (stock no. 004669) mice were purchased from the Jackson Laboratory (Maine, USA). All the mice used in the study were female 6-8week-old C57BL/6J mice. WT and $\mathrm{C} 25 \mathrm{H} \mathrm{KO}$ mice were injected intraperitoneally with MDP $(20 \mathrm{mg} / \mathrm{kg})$. C25H KO mice were also injected intraperitoneally with $25 \mathrm{HC}(50 \mathrm{mg} / \mathrm{kg})$. At $4 \mathrm{~h}$ post treatment, serum was collected from treated mice. In order to study the role of the integrin-FAK pathway in promoting 25HC-mediated proinflammatory response in mice, we analyzed IL-6 levels in mouse lungs after $25 \mathrm{HC}$ administration to the airway in the presence of either $\beta 1$ integrin blocking antibody (anti-mouse CD29, clone-9EG7; BD Pharmigen, California, USA) or FAK inhibitor PND-1186 (MedKoo Biosciences, North Carolina, USA). Female 6-8week-old C57BL/6J mice were injected intratracheally with either IgG or $\beta 1$ integrin blocking antibody $(20 \mu \mathrm{g} / \mathrm{ml})$. At $2 \mathrm{~h}$ post treatment, mice were injected intratracheally with either vehicle control (ethanol) or $25 \mathrm{HC}(5 \mathrm{mg} / \mathrm{kg})$. At $6 \mathrm{~h}$ post $25 \mathrm{HC}$ treatment, lungs were isolated. IL-6 levels in the lung homogenate were analyzed by ELISA. In a separate experiment, female 6-8-week-old C57BL/6 mice were injected intratracheally with either vehicle control (water) or FAK inhibitor PND-1186 $(50 \mathrm{mg} / \mathrm{kg})$. At $1 \mathrm{~h}$ post treatment, mice were injected intratracheally with either vehicle control (ethanol) or $25 \mathrm{HC}(5 \mathrm{mg} / \mathrm{kg})$. At $6 \mathrm{~h}$ post $25 \mathrm{HC}$ 
treatment, lungs were isolated. IL-6 levels in the lung homogenate was analyzed by ELISA. In some experiment, mice were infected with influenza A virus (IAV). Female 6-8-week-old C57BL/6J mice were intratracheally inoculated with either medium (vehicle control) or IAV $\left(1 \times 10^{4} \mathrm{pfu} /\right.$ mouse $)$. At 2 days post infection, lungs were isolated. $25 \mathrm{HC}$ levels in the lung homogenate was analyzed by $25 \mathrm{HC}$ detection kit. Animal experiments were approved and carried out in accordance with the guidelines established by the Institutional Animal Care and Use Committee (IACUC) of Washington State University.

Integrin blocking. Cell surface $\alpha 5 \beta 1$ and $\alpha v \beta 3$ integrin were inhibited in vitro by pre-treating cells with $\alpha 5 \beta 1$ integrin $(75 \mu \mathrm{g} / \mathrm{ml}, \mathrm{MAB} 2514)$ and $\alpha v \beta 3$ integrin (10 $\mu \mathrm{g} / \mathrm{ml}$, LM609) blocking antibody (Millipore, Massachusetts, USA), respectively. IgG served as a control for the experiments. Following pre-treatment, cells were either infected with viruses (RSV and IAV) or treated with 25HC and MDP. For in vivo experiments, mice were treated with either IgG (control) or $\beta 1$ integrin blocking antibody (anti-mouse CD29, clone-9EG7).

Silencing with siRNA. Differentiated human THP-1 macrophages were transfected with either $100 \mathrm{pmol}$ of control siRNA or human $\alpha 5$ integrin siRNA using Lipofectamine 2000 (Invitrogen, California, USA). At $16 \mathrm{~h}$ post transfection, cells were treated with either MDP or $25 \mathrm{HC}$. Control siRNA and human $a 5$ integrin siRNA were purchased from Santa Cruz Biotechnology (Texas, USA).

Western blotting. FAK activation was assessed by performing western blotting with phospho-FAK (mouse Tyr925; catalog no. 3284 and human Tyr397; catalog no. 8556) (1:500) and FAK (1:1000) antibodies (catalog no. 13009) (Cell Signaling, Massachusetts, USA). Western blotting with IкB (catalog no. 4812) (1:1000) and phospho-IKB (catalog no. 2859) (1:1000) antibodies (Cell Signaling) was performed to examine NFkB activation status. As indicated, a5 integrin (catalog no. ab150361) (1:500) and av integrin (catalog no. ab179475) (1:1000) antibodies (Abcam, Cambridge, UK) were also used for western blot analyses. The actin antibody (catalog no. A300-485A) (1:5000) was purchased from Bethyl Laboratories (Texas, USA). In some experiments, protein bands from the western blots were quantified by using ChemiDoc ${ }^{\text {mm }}$ XRS + software Image Lab 5.1 (BioRad). Uncropped western blots are shown in Supplementary Fig. 10.

Cytokine and 25HC detection assay. TNF and IL-6 levels in the medium supernatant and mice serum were assessed by using a specific ELISA kit (eBioscience, California, USA). 25HC levels in the medium supernatant and mice serum were measured with a 25HC detection kit (MyBiosource, California, USA). Please note that for the macrophages, the ELISA values of the experimental group (i.e., 25HC, MDP-treated cells or RSV, IAV-infected cells) represent values obtained following subtraction of background signal measured in the control group (i.e., vehicle-treated cells or mock-infected cells). The background values for the MEF control group were below the detection limit of the ELISA kit.

Lactate dehydrogenase cytotoxicity assay. LDH-Cytotoxicity Assay kit-II (BioVision, California, USA) was used to evaluate cell viability. Briefly, medium supernatant was incubated with LDH Reaction Mix. The absorbance at $450 \mathrm{~nm}$ was then measured using a micro-plate reader. Percent cytotoxicity was calculated according to the manufacturer's instructions. As a positive control, cells were treated with a supplier provided agent that induces cellular toxicity.

\section{Biotinylation of 25HC. The EZ-link ${ }^{\circledR}$ TFPA-PEG3-Biotin kit (Thermo Fisher} Scientific, Massachusetts, USA) was used to biotinylate 25HC. This kit is appropriate for biotinylating non-protein macromolecules like lipids. As DMSO was the vehicle for $25 \mathrm{HC}$ we also treated an equal volume of DMSO to serve as a control. Please note that we do not expect DMSO to be biotinylated as it does not possess the necessary side-groups for the biotinylation reaction. Biotinylation was performed in the dark as per the manufacturer's instructions. To assess successful biotinylation of $25 \mathrm{HC}$, biotin-25HC was pulled down with NeutrAvidin-agarose beads (Thermo Fisher Scientific) and avidin bound material was eluted by incubating the beads with $10 \mathrm{mM} \mathrm{EDTA}$ and $95 \%$ formamide at a pH of 8.2 for $15 \mathrm{~min}$. Eluted material was assessed for $25 \mathrm{HC}$ using a $25 \mathrm{HC}$ detection kit. In addition to 25HC, 27-hydroxycholesterol (27HC) (Steraloids), and $4 \beta$-hydroxycholesterol $(4 \beta \mathrm{HC})$ (Steraloids) were also biotinylated.

Interaction of biotinylated 25HC with integrins. Macrophages (BMDMs) were pre-cooled to $4{ }^{\circ} \mathrm{C}$ for $1 \mathrm{~h}$, then incubated at $4^{\circ} \mathrm{C}$ with either biotin-25HC $(50 \mu \mathrm{M})$ or DMSO control for $4 \mathrm{~h}$. Cells were lysed with $1 \%$ TritonX-100 (Sigma) and protease inhibitor (Roche, Basel, Switzerland) in PBS. Cell lysates were incubated with NeutrAvidin-agarose beads (Thermo Fisher Scientific) $\left(12 \mathrm{~h}\right.$ at $\left.4{ }^{\circ} \mathrm{C}\right)$. After exhaustively washing the agarose beads with wash buffer (10 mM Tris-HCL and protease inhibitor in PBS), the proteins bound to avidin-agarose beads were subjected to western blotting with integrin antibodies. This experiment was repeated using biotin-25HC, biotin-27HC, and biotin-4 $3 \mathrm{HC}$

Biotin-25HC was also used to assess direct binding of $25 \mathrm{HC}$ to purified integrin proteins. Biotin-25HC was incubated $\left(12 \mathrm{~h}\right.$ at $\left.4{ }^{\circ} \mathrm{C}\right)$ with avidin-agarose beads.
These complexes were then further incubated $\left(12 \mathrm{~h}\right.$ at $\left.4{ }^{\circ} \mathrm{C}\right)$ with purified $\alpha 5 \beta 1$ integrin or av $\beta 3$ integrin, which were purchased from Yo proteins $A B$ (Huddinge, Sweden). After exhaustively washing the agarose beads, the avidin-agarose bound proteins were subjected to western blotting with $\alpha 5$ and $\alpha v$ integrin antibodies.

Interaction of tritiated ${ }^{3} \mathbf{H}-\mathbf{2 5 H C}$ with integrins. ${ }^{3} \mathrm{H}-25 \mathrm{HC}$ was purchased from PerkinElmer (Massachusetts, USA). Protein G agarose beads were incubated ( $12 \mathrm{~h}$, $4^{\circ} \mathrm{C}$ ) with control $\mathrm{IgG}$ or antibodies against $\alpha 5$ or av integrin. Antibodyconjugated beads were then incubated $\left(12 \mathrm{~h}, 4^{\circ} \mathrm{C}\right)$ with purified $\alpha 5 \beta 1$ and $\alpha v \beta 3$ integrin proteins (Yo proteins $\mathrm{AB}$, Huddinge, Sweden). The antibody-antigen bound beads were washed and incubated with ${ }^{3} \mathrm{H}-25 \mathrm{HC}(0.01 \mu \mathrm{Ci})$ for $12 \mathrm{~h}$ at $4{ }^{\circ} \mathrm{C}$. Following incubation, the beads were exhaustively washed and bound radioactivity was counted using a TRI-CARB 2900TR liquid scintillation counter.

Reverse transcription-PCR (RT-PCR). Total RNA was extracted using TRIzol reagent (Life Technologies, California, USA) following the manufacturer's instructions. MultiScribe reverse transcriptase (Applied Biosystem, California, USA) was used to synthesize template cDNA. PCR was performed using Apex ${ }^{\oplus} 2 \mathrm{X}$ Taq Red master mix (Genesee Scientific, California, USA) in a final reaction volume of $25 \mu \mathrm{l}$. The amplified PCR products were visualized in a 1-2\% agarose gel. Amplified glyceraldehyde-3-phosphate dehydrogenase (GAPDH) gene PCR product was used as a loading control. PCR primers for each gene are listed in Supplementary Table 3.

Immunofluorescence microscopy. Cell preparations were processed for laser scan confocal immunofluorescence microscopy ${ }^{57}$. Briefly, A549 and THP-1 cells grown on coverslips were incubated with DMSO (vehicle control) or $0.5 \mu \mathrm{M} 25 \mathrm{HC}$ for $2 \mathrm{~h}$ They were then fixed by incubation with $3.7 \%$ formaldehyde for $5 \mathrm{~min}$ and extracted with $0.5 \%$ TritonX-100 for 7 min. Primary antibodies, diluted 1:100, were incubated in a solution of $0.05 \%$ tween- 20 and $5 \%$ normal goat serum (Jackson ImmunoResearch Laboratories, Pennsylvania, USA) in PBS for $1 \mathrm{~h}$ at $37^{\circ} \mathrm{C}$. The mouse monoclonal antibody against $\alpha v \beta 3$ integrin (MAB1976Z, clone LM609) were purchased from Millipore. The mouse monoclonal antibody against active $\beta 3$ integrin (EBW107, clone AP5) was purchased from Kerafast (Massachusetts, USA) The rabbit monoclonal antibody against paxillin (ab32084, clone Y113) was purchased from Abcam. Secondary antibodies, diluted 1:200, were incubated in $0.05 \%$ tween-20 in PBS for $1 \mathrm{~h}$ at $37^{\circ} \mathrm{C}$. The fluorescein-conjugated goat anti-mouse IgG (115-095-166) and rhodamine-conjugated goat anti-rabbit IgG (111-025-144) antibodies were purchased from Jackson ImmunoResearch Laboratories. Samples were imaged at room temperature using a TCS SP5 confocal microscope equipped with a $63 \times 1.4$ NA objective and version 2.4.1 (build 6384) of the LASAF imaging suite (Leica Microsystems, Illinois, USA). Analyses of focal adhesions and podosomes were performed by counting the number present per cell when treated with DMSO or $0.5 \mu \mathrm{M} 25 \mathrm{HC}$ for $2 \mathrm{~h}$. Such experiments were repeated three times and followed by one-sided Wilcoxon rank-sum tests to compare conditions.

Analyses of focal adhesions were performed as described by us ${ }^{58}$ and others ${ }^{59}$. Analyses of focal adhesions were performed by counting all distinct fluorescently labeled integrin clusters that localized to the basal portion of cell surface when viewed via confocal microscopy following a $2 \mathrm{~h}$ treatment with DMSO or $0.5 \mu \mathrm{M}$ $25 \mathrm{HC}$. Using ImageJ and constant parameters for each experiment, background was subtracted, local contrast was enhanced by using CLAHE ${ }^{60}$, and thresholding was performed. Contiguous blocks of thresholded pixels were grouped together to define focal adhesions using the R package Bioi ${ }^{61}$.

Cell motility assays. Cells were imaged every $5 \mathrm{~min}$ for $2 \mathrm{~h}$ using a DMi8 conventional fluorescent microscope (Leica Microsystems) equipped with a $5 \times 0.12$ NA objective, a $37^{\circ} \mathrm{C}$ heated chamber (Pathology Devices), and a DFC365 FX FCAM2 camera. Images were acquired using the LAS X image acquisition suite (version 1.0.0.12269). Cell positions were tracked using image cross-correlation velocimetry as implemented in MetaMorph software version 7.8.0.0 (Molecular Devices, California, USA). Cell positions were used to calculate speed and processivity. The latter was defined as the maximum displacement from a cell's origin divided by the length of the path it traveled.

Integrin internalization assay. $\alpha v \beta 3$ integrin internalization was assayed using established protocols ${ }^{62}$. Briefly, $24 \mathrm{~h}$ after plating onto glass coverslips, A549 cells were treated for $30 \mathrm{~min}$ on ice with antibodies against av $\beta 3$ integrin (1:100 in culture medium, MAB1976Z, Millipore) and then again with fluoresceinconjugated goat anti-mouse antibodies (1:200 in culture medium, 115-095-166, Jackson ImmunoResearch Laboratories). This was followed by a 30 min incubation at $37^{\circ} \mathrm{C}$ in culture medium supplemented with DMSO or $0.5 \mu \mathrm{M} 25 \mathrm{HC}$. Finally, cells were incubated for $30 \mathrm{~min}$ on ice with rhodamine-conjugated goat anti-mouse antibodies (1:200 in culture medium, 115-025-166, Jackson ImmunoResearch Laboratories). Samples were imaged using a TCS SP5 confocal microscope (Leica Microsystems). Internalization was quantified by calculating Spearman's correlation between the two fluorescent channels for all pixels exceeding the background fluorescence level in the fluorescein channel. 
Surface plasmon resonance studies. To study biomolecular interaction between integrin and $25 \mathrm{HC}$ in real-time, SPR was performed using a Biacore 3000 instrument (GE Healthcare, Piscataway, New Jersey) according to the manufacturer's instructions. Purified human $\alpha v \beta 3$ integrin protein (Yo proteins $A B$, Huddinge, Sweden) was covalently immobilized on a flow cell of CM5 chip (carboxy-methylated dextran coated) in $10 \mathrm{mM}$ sodium acetate buffer, $\mathrm{pH} 4.0$, using EDC/NHS amine coupling chemistry at $25^{\circ} \mathrm{C}$. The unused dextran surface was then inactivated by injecting $1 \mathrm{M}$ Ethanolamine, $\mathrm{pH}$ 8.5. Similarly, the blank control flow cell was simultaneously activated and inactivated without the protein for background subtraction of any non-specific response. For kinetic analyses, increasing concentrations of $25 \mathrm{HC}(0 \mathrm{nM}, 16 \mathrm{nM}, 40 \mathrm{nM}, 160 \mathrm{nM}, 640 \mathrm{nM}, 1.6$ $\mu \mathrm{M})$ in the running buffer HBS-P (10 mM HEPES, $0.15 \mathrm{M} \mathrm{NaCl}, 0.005 \%$ polysorbate $20, \mathrm{pH} 7.4$ ) with $1 \%$ DMSO were injected at a flow rate of $20 \mu \mathrm{l} / \mathrm{min}$ for $150 \mathrm{~s}$. Following dissociation, the chip surface was regenerated with the running buffer. The background subtracted SPR sensorgrams were quantitatively evaluated to determine $K_{\mathrm{D}}$ (apparent affinity constant) by using the Biacore 3000 Evaluation Software (GE Healthcare) and the Langmuir 1:1 binding model.

Competitive binding analyses. A modified version of "ELISA-type" binding assay ${ }^{34-36}$ was used to study binding of $25 \mathrm{HC}$ to human $\alpha v \beta 3$ integrin protein in the absence and presence of the competitor comprising of purified chemokine domain (CD) of recombinant human fractalkine protein (Peprotech, New Jersey, USA). For this assay, 96-well Nunc micro-well plate (Thermo Fisher Scientific) was coated with purified human av $\beta 3$ integrin protein (200 ng of protein/well in PBS containing $1 \mathrm{mM} \mathrm{MnCl})^{35,63}$. Following incubation $\left(16 \mathrm{~h}, 4^{\circ} \mathrm{C}\right)$, the wells were washed with $\mathrm{PBS} / 0.1 \% \mathrm{BSA}$ and subsequently blocked with $\mathrm{PBS} / 2 \% \mathrm{BSA}$ for $3 \mathrm{~h}$ (at room temperature). Blocked wells were washed with PBS/0.1\% BSA and then either vehicle (water) or purified fractalkine-CD protein (1000 ng/well in HEPES-Tyrodes buffer) was added to the wells. Following $2 \mathrm{~h}$ incubation (at room temperature), the wells were washed with PBS/0.1\% BSA, and subsequently ${ }^{3} \mathrm{H}-25 \mathrm{HC}$ (in PBS/0.5\% BSA) was added to the wells. Following $16 \mathrm{~h}$ incubation (at $4{ }^{\circ} \mathrm{C}$ ), the wells were washed with $\mathrm{PBS} / 0.1 \% \mathrm{BSA}$ and the bound radioactivity (representing ${ }^{3} \mathrm{H}-25 \mathrm{HC}$ bound to $a v \beta 3$ integrin in the absence and presence of fractalkine-CD protein) was counted using a TRI-CARB 2900TR liquid scintillation counter.

Molecular modeling studies. The three-dimensional (3D) structure of the ligand molecule 25HC was built in Molecular Operating Environment (MOE) (Chemical Computing Group, Montreal, Canada) and subsequently geometry optimized and Mulliken charge calculations were performed in Gaussian16 program (Gaussian, Wallingford, Connecticut, USA) using the DFT/B3LYP method and the $6-31 G^{* *}$ basis set.

Molecular docking and dynamics studies were conducted using the published crystal structures of extracellular domains of integrins $\alpha \mathrm{v} \beta 3$ (PDB code 1L5G and 3IJE) in complex with ARG-GLY-ASP (RGD) ligand ${ }^{64}$ and unbound states, respectively. The crystal structure was prepared using "Protein Preparation" module in MOE (missing atoms, residues, and $\mathrm{H}$ atoms were added, protonation states of residues were assigned using protonate $3 \mathrm{D}$ within the MOE). The crystal structure (PDB code 3IJE) represents the complete unconstrained ectodomain ${ }^{65}$ and short C-terminal transmembrane stretches of the av and $\beta 3$ subunits.

Molecular docking of $25 \mathrm{HC}$ at the classical 'RGD"-binding site (site I), as well as site-II was performed in MOE. The ligand molecule was docked using guideddocking mode in which the "RGD" cyclic peptide bound to $\alpha v \beta 3^{64}$ was used as a template to place $25 \mathrm{HC}$ within the binding site. For site-II positioning, the integrin-binding site was defined by selected residues (Supplementary Table 2).

Two placement methods namely Alpha PMI, and Alpha Triangle and Proxy Triangle were employed to generate best-docked poses of $25 \mathrm{HC}$. In the Alpha PMI method, poses are generated by aligning ligand conformations' principal moments of inertia to a randomly generated subset of alpha spheres in the receptor site. Whereas in the Alpha Triangle and Proxy triangle method, poses are generated by superposition of the ligand atom triplets and triplets of receptor site points representing locations of tight packing. The protein-ligand complex structures generated by the placement method were further refined by induced fitting of protein side chains while the backbone atoms were held fixed. The generated poses were scored using the enthalpy-based "Affinity dG" scoring function, followed by the "London $\mathrm{dG}^{\text {" scoring function }}{ }^{66}$ at the refinement stage.

All MD simulations were performed using the AMBER16 package ${ }^{67}$ under isothermal/isobaric (NPT) ensemble with periodic boundary conditions. The AMBER ff14SB force field, General AMBER force field (GAFF) ${ }^{68}$, and TIP3P 69 water model were employed for the protein, including bivalent and monovalent ions, $25 \mathrm{HC}$, and solvent molecules, respectively. We used the Leap program from Antechamber tools (AmberTools14) 70 $^{70}$ generate the parameter/topology and input coordinate files. The net charge of the integrin-25HC complex was kept neutral by adding $34 \mathrm{Na}^{+}$ions at positions of high-negative electron potential around the protein-ligand complex. The system was immersed in a truncated octahedral box of pre-equilibrated TIP3P water molecules in such a way that no atoms in the protein-ligand complex were closer than $8 \AA$ to any of the sides of the solvent box. The counter ions and solvent molecules were briefly minimized (1000 steps of steepest descent minimization followed by another 1000 steps of conjugate gradient method) to remove any bad contacts with the complexes. The rest of the system was position-restrained using a force constant of $100 \mathrm{kcal} /(\mathrm{mol} \times$ $\AA^{2}$ ). This step was followed by another 2000 step minimization of the whole solvated complex. The readjustment of solvent molecules to the potential field of the protein-ligand complex was achieved by subsequent heating and equilibration steps. The system was heated to a final temperature of $300 \mathrm{~K}$ in three steps: 0 to $100 \mathrm{~K}$ for $10 \mathrm{ps}$ (NVT), 100 to $200 \mathrm{~K}$ for $20 \mathrm{ps}$, and 200 to $300 \mathrm{~K}$ for another $20 \mathrm{ps}$, all under NPT conditions ( 1 atm pressure). Isotropic position scaling was used to maintain the pressure, and a relaxation time of 2 ps was used. During the heating phases, the protein-ligand complexes were position-restrained with a force constant of $10 \mathrm{kcal} /\left(\mathrm{mol} \times \AA^{2}\right)$. Langevian dynamics was used in all stages to control the temperature using a collision frequency of $1.0 \mathrm{ps}^{-1}$. The final solvent equilibration step was performed for 50 ps under NPT conditions as above. The SHAKE algorithm was used to constrain bonds involving hydrogen, allowing a time step of $2 \mathrm{fs}$. Lennard-Jones and electrostatic interactions were calculated explicitly within a cutoff of $1.2 \mathrm{~nm}$, and long range electrostatic interactions were calculated by particle mesh Ewald summation. The production simulation was carried out for $200 \mathrm{~ns}$ and the trajectory file was written for every 20,000 steps resulting in 20,000 frames.

The unbound and bound forms of integrin-25HC complexes from MD simulations were analyzed for its conformational change and structural integrity of both $\alpha$ - and $\beta$-subunits. The secondary structures and overall integrity of the interacting domains were found to be stable throughout the simulation period. Principal component analyses (PCA) was performed to characterize the cumulative and overall motion of the av $\beta 3$ integrin, resulting from the atomic fluctuations due to $25 \mathrm{HC}$ binding. The PCA analyses was performed using ProDy ${ }^{71}$ interface in NMWiz (Normal Model Wizard) plugin implemented in VMD. In PCA analyses, the first principal component typically consists of the largest root-mean-square fluctuation (RMSF). The correlation matrices were calculated from the massadjusted Cartesian coordinates representing ensemble average of all snapshots from the production phase $(200 \mathrm{~ns})$ simulation. We have restricted the analyses to only $\mathrm{C} \alpha$ atoms, as they are less perturbed by statistical noise and provide significant characterization of the essential space motions. Comparative analyses of both bound and unbound species was performed by calculating the cross-correlation matrices, using Carma 1.7 program ${ }^{72}$ to investigate the dynamic cross-correlated displacements of $\mathrm{C} \alpha$ atoms of $\alpha v \beta 3$ in the MD simulation trajectories. To visualize the direction and extent of the principal motions of $\alpha v \beta 3$ in its bound state, porcupine plot analyses was performed using the PorcupinePlot.tcl script in VMD.

Statistical approach. ELISA data were analyzed using Graphpad Prism software (6.0) and significance test was carried out using Student's $t$-test. Densitometric values of the western blots were quantified by using ChemiDoc ${ }^{\mathrm{mm}}$ XRS + software Image Lab 5.1 (BioRad) and significance test was carried out using Student's $t$-test Immunocytochemistry and cell motility data were analyzed using one-way and two-way Wilcoxon rank-sum tests.

Reporting Summary. Further information on experimental design is available in the Nature Research Reporting Summary linked to this article.

\section{Data availability}

The data supporting the findings are available within the article and Supplementary Information. The source data of Figs 1c-f, 2e-i, 4b, c, 5a, e-g, 6a, c-f, h, i, k, l, 7a, b, e-l, and Supplementary Figs. 1a, b, 2a, b, d, $4 a-c, 6 a-c, f, 7 b-h$ are provided as a Source Data file. All other data are available from the authors upon reasonable request.

Received: 22 February 2018 Accepted: 13 March 2019

Published online: 01 April 2019

\section{References}

1. Guo, W. \& Giancotti, F. G. Integrin signalling during tumour progression. Nat. Rev. Mol. Cell Biol. 5, 816-826 (2004).

2. Hynes, R. O. Integrins: bidirectional, allosteric signaling machines. Cell 110, 673-687 (2002).

3. Shattil, S. J., Kim, C. \& Ginsberg, M. H. The final steps of integrin activation: the end game. Nat. Rev. Mol. Cell Biol. 11, 288-300 (2010).

4. Lelievre, S., Weaver, V. M. \& Bissell, M. J. Extracellular matrix signaling from the cellular membrane skeleton to the nuclear skeleton: a model of gene regulation. Recent Prog. Horm. Res. 51, 417-432 (1996).

5. Eke, I. et al. beta(1)Integrin/FAK/cortactin signaling is essential for human head and neck cancer resistance to radiotherapy. J. Clin. Invest. 122, 1529-1540 (2012).

6. Campbell, I. D. \& Humphries, M. J. Integrin structure, activation, and interactions. Cold Spring Harb. Perspect. Biol. 3, a004994 (2011).

7. Zhu, J., Zhu, J. \& Springer, T. A. Complete integrin headpiece opening in eight steps. J. Cell Biol. 201, 1053-1068 (2013). 
8. Müller, M. A. et al. The glycophorin A transmembrane sequence within integrin av $\beta 3$ creates a non-signaling integrin with low basal affinity that is strongly adhesive under force. J. Mol. Biol. 425, 2988-3006 (2013).

9. Ye, F., Snider, A. K. \& Ginsberg, M. H. Talin and kindlin: the one-two punch in integrin activation. Front. Med. 8, 6-16 (2014).

10. Calderwood, D. A., Campbell, I. D. \& Critchley, D. R. Talins and kindlins: partners in integrin-mediated adhesion. Nat. Rev. Mol. Cell Biol. 14, 503-517 (2013).

11. Murphy, D. A. \& Courtneidge, S. A. The'ins' and'outs' of podosomes and invadopodia: characteristics, formation and function. Nat. Rev. Mol. Cell Biol. 12, 413-426 (2011).

12. Reyes-Reyes, M., Mora, N., Zentella, A. \& Rosales, C. Phosphatidylinositol 3kinase mediates integrin-dependent NF-( $\kappa)$ B and MAPK activation through separate signaling pathways. J. Cell Sci. 114, 1579-1589 (2001).

13. Kawai, T. \& Akira, S. The role of pattern-recognition receptors in innate immunity: update on Toll-like receptors. Nat. Immunol. 11, 373-384 (2010).

14. Sabbah, A. et al. Activation of innate immune antiviral responses by Nod2. Nat. Immunol. 10, 1073-1080 (2009).

15. Coutermarsh-Ott, S., Eden, K. \& Allen, I. C. Beyond the inflammasome: regulatory NOD-like receptor modulation of the host immune response following virus exposure. J. Gen. Virol. 97, 825-838 (2016).

16. Lupfer, C., Thomas, P. G. \& Kanneganti, T. -D. Nucleotide oligomerization and binding domain 2-dependent dendritic cell activation is necessary for innate immunity and optimal CD8 $+\mathrm{T}$ cell responses to influenza A virus infection. J. Virol. 88, 8946-8955 (2014).

17. Lupfer, C. et al. Receptor interacting protein kinase 2-mediated mitophagy regulates inflammasome activation during virus infection. Nat. Immunol. 14, 480-488 (2013).

18. Nakamura, N. et al. Endosomes are specialized platforms for bacterial sensing and NOD2 signalling. Nature 509, 240-244 (2014).

19. Kim, Y. G. et al. Viral infection augments Nod1/2 signaling to potentiate lethality associated with secondary bacterial infections. Cell Host Microbe 9 496-507 (2011).

20. Kapoor, A., Forman, M. \& Arav-Boger, R. Activation of nucleotide oligomerization domain 2 (NOD2) by human cytomegalovirus initiates innate immune responses and restricts virus replication. PLOS ONE $\mathbf{9}$, e92704 (2014).

21. Davoli-Ferreira, M. et al. Nucleotide-binding oligomerization domaincontaining protein 2 prompts potent inflammatory stimuli during Neospora caninum infection. Sci. Rep. 6, 29289 (2016).

22. Ley, K., Rivera-Nieves, J., Sandborn, W. J. \& Shattil, S. Integrin-based therapeutics: biological basis, clinical use and new drugs. Nat. Rev. Drug. Discov. 15, 173-183 (2016).

23. Nieberler, M. et al. Exploring the role of RGD-recognizing integrins in cancer. Cancers (Basel) 9, 116 (2017).

24. Cyster, J. G., Dang, E. V., Reboldi, A. \& Yi, T. 25-Hydroxycholesterols in innate and adaptive immunity. Nat. Rev. Immunol. 14, 731-743 (2014).

25. Lund, E. G., Kerr, T. A., Sakai, J., Li, W. -P. \& Russell, D. W. cDNA cloning of mouse and human cholesterol 25-hydroxylases, polytopic membrane proteins that synthesize a potent oxysterol regulator of lipid metabolism. J. Biol. Chem. 273, 34316-34327 (1998).

26. Gold, E. S. et al. 25-Hydroxycholesterol acts as an amplifier of inflammatory signaling. Proc. Natl Acad. Sci. 111, 10666-10671 (2014).

27. Chen, J. et al. $\alpha v \beta 3$ integrins mediate flow-induced NF-kB activation, proinflammatory gene expression, and early atherogenic inflammation. Am. J. Pathol. 185, 2575-2589 (2015)

28. Yurdagul, A. et al. $\alpha 5 \beta 1$ integrin signaling mediates oxidized low-density lipoprotein-induced inflammation and early atherosclerosis. Arterioscler. Thromb. Vasc. Biol. 114, 1362-1373 (2014).

29. Takagi, J., Strokovich, K., Springer, T. A. \& Walz, T. Structure of integrin alpha5beta1 in complex with fibronectin. EMBO J. 22, 4607-4615 (2003).

30. Calderwood, D. A., Tuckwell, D. S., Eble, J., Kuhn, K. \& Humphries, M. J. The integrin alpha1 A-domain is a ligand binding site for collagens and laminin. J. Biol. Chem. 272, 12311-12317 (1997).

31. Lechner, A. M. et al. RGD-dependent binding of procathepsin X to integrin alphavbeta3 mediates cell-adhesive properties. J. Biol. Chem. 281, 39588-39597 (2006).

32. Saegusa, J. et al. The direct binding of insulin-like growth factor-1 (IGF-1) to integrin $\alpha v \beta 3$ is involved in IGF-1 signaling. J. Biol. Chem. 284, 24106-24114 (2009).

33. Saegusa, J. et al. Pro-inflammatory secretory phospholipase A2 type IIA binds to integrins alphavbeta 3 and alpha4betal and induces proliferation of monocytic cells in an integrin-dependent manner. J. Biol. Chem. 283, 26107-26115 (2008)

34. Fujita, M., Takada, Y. K. \& Takada, Y. Integrins av $\beta 3$ and $\alpha 4 \beta 1$ act as coreceptors for fractalkine, and the integrin-binding defective mutant of fractalkine is an antagonist of CX3CR1. J. Immunol. 189, 5809-5819 (2012).
35. Fujita, M., Takada, Y. K. \& Takada, Y. The chemokine fractalkine can activate integrins without CX3CR1 through direct binding to a ligandbinding site distinct from the classical RGD-binding site. PLoS ONE 9, e96372 (2014).

36. Fujita, M. et al. Proinflammatory secreted phospholipase A2 type IIA (sPLAIIA) induces integrin activation through direct binding to a newly identified binding site (site 2) in integrins $\alpha v \beta 3$, $\alpha 4 \beta 1$, and $\alpha 5 \beta 1$. J. Biol. Chem. 290 , 259-271 (2015).

37. Bissantz, C., Kuhn, B. \& Stahl, M. A medicinal chemist's guide to molecular interactions. J. Med. Chem. 53, 5061-5084 (2010).

38. Takada, Y., Kamata, T., Irie, A., Puzon-McLaughlin, W. \& Zhang, X. -P. Structural basis of integrin-mediated signal transduction. Matrix Biol. 16, 143-151 (1997).

39. Yokoyama, K., Zhang, X. -P., Medved, L. \& Takada, Y. Specific binding of integrin $\alpha v \beta 3$ to the fibrinogen $\gamma$ and $\alpha \mathrm{E}$ chain C-terminal domains. Biochemistry 38, 5872-5877 (1999).

40. Takagi, J., DeBottis, D. P., Erickson, H. P. \& Springer, T. A. The role of the specificity-determining loop of the integrin $\beta$ subunit I-like domain in autonomous expression, association with the a subunit, and ligand binding. Biochemistry 41, 4339-4347 (2002).

41. Berendsen, H. J. \& Hayward, S. Collective protein dynamics in relation to function. Curr. Opin. Struct. Biol. 10, 165-169 (2000).

42. Xiao, T., Takagi, J., Coller, B. S., Wang, J. -H. \& Springer, T. A. Structural basis for allostery in integrins and binding to fibrinogen-mimetic therapeutics. Nature 432, 59-67 (2004).

43. Lee, C. C., Carette, J. E., Brummelkamp, T. R. \& Ploegh, H. L. A reporter screen in a human haploid cell line identifies CYLD as a constitutive inhibitor of NF-kB. PLoS ONE 8, e70339 (2013).

44. Liu, S. Y. et al. Interferon-inducible cholesterol-25-hydroxylase broadly inhibits viral entry by production of 25 -hydroxycholesterol. Immunity $\mathbf{3 8}$, 92-105 (2013).

45. Grassmé, H. et al. $\beta 1$-Integrin accumulates in cystic fibrosis luminal airway epithelial membranes and decreases sphingosine, promoting bacterial infections. Cell Host Microbe 21, 707-718.e708 (2017).

46. Walsh, C. et al. Oral delivery of PND-1186 FAK inhibitor decreases tumor growth and spontaneous breast to lung metastasis in pre-clinical models. Cancer Biol. Ther. 9, 778-790 (2010).

47. Humphries, J. D., Byron, A. \& Humphries, M. J. Integrin ligands at a glance. J. Cell. Sci. 119, 3901-3903 (2006).

48. Hubbard, A. K. \& Rothlein, R. Intercellular adhesion molecule-1 (ICAM-1) expression and cell signaling cascades. Free Radic. Biol. Med. 28, 1379-1386 (2000).

49. Maile, L. A. et al. Insulin-like growth factor-I signaling in smooth muscle cells is regulated by ligand binding to the 177CYDMKTTC184 sequence of the $\beta 3$ subunit of aVß3. Mol. Endocrinol. 20, 405-413 (2006).

50. Artoni, A. et al. Integrin $\beta 3$ regions controlling binding of murine $\mathrm{mAb} 7 \mathrm{E} 3$ : Implications for the mechanism of integrin aIIb $\beta 3$ activation. Proc. Natl Acad. Sci. USA 101, 13114-13120 (2004).

51. Hermanowski-Vosatka, A., Van Strijp, J. A., Swiggard, W. J. \& Wright, S. D. Integrin modulating factor-1: a lipid that alters the function of leukocyte integrins. Cell 68, 341-352 (1992).

52. Bauman, D. R. et al. 25-Hydroxycholesterol secreted by macrophages in response to Toll-like receptor activation suppresses immunoglobulin A production. Proc. Natl Acad. Sci. USA 106, 16764-16769 (2009).

53. Blanc, M. et al. The transcription factor STAT-1 couples macrophage synthesis of 25-hydroxycholesterol to the interferon antiviral response. Immunity 38, 106-118 (2013).

54. McDonald, J. G. \& Russell, D. W. Editorial: 25-Hydroxycholesterol: a new life in immunology. J. Leukoc. Biol. 88, 1071-1072 (2010).

55. Reboldi, A. et al. 25-Hydroxycholesterol suppresses interleukin-1-driven inflammation downstream of type I interferon. Sci. (New Y., N. Y.) $\mathbf{3 4 5}$, 679-684 (2014).

56. Tsai, S. Y. et al. DAMP molecule S100A9 acts as a molecular pattern to enhance inflammation during influenza A virus infection: role of DDX21TRIF-TLR4-MyD88 pathway. PLoS Pathog. 10, e1003848 (2014).

57. Kligys, K. R. et al. a6 $\beta 4$ integrin, a master regulator of expression of integrins in human keratinocytes. J. Biol. Chem. 287, 17975-17984 (2012).

58. Colburn, Z. T. \& Jones, J. C. R. Complexes of alpha6beta4 integrin and vimentin act as signaling hubs to regulate epithelial cell migration. J. Cell Sci. 131, pii: jcs214593 (2018).

59. Horzum, U., Ozdil, B. \& Pesen-Okvur, D. Step-by-step quantitative analysis of focal adhesions. MethodsX 1, 56-59 (2014).

60. Saalfeld, S. CLAHE (Contrast Limited Adaptive Histogram Equalization). http://rsbweb.nih.gov/ij/plugins/clahe/index.html (2009) .

61. Colburn, Z. Bioi. Zenodo. https://doi.org/10.5281/zenodo.1289808 (2018).

62. Marjomaki, V. et al. $\alpha 2 \beta 1$-integrin clustering and internalization protocol. Bio-Protoc. 4, e1088 (2014). 
63. Trad, A. et al. The disintegrin domain of ADAM17 antagonises fibroblastcarcinoma cell interactions. Int. J. Oncol. 42, 1793-1800 (2013).

64. Xiong, J. -P. et al. Crystal structure of the extracellular segment of integrin $\alpha \mathrm{V} \beta 3$ in complex with an Arg-Gly-Asp ligand. Science 296, 151-155 (2002).

65. Xiong, J. -P. et al. Crystal structure of the complete integrin $\alpha \mathrm{V} \beta 3$ ectodomain plus an $\alpha / \beta$ transmembrane fragment. J. Cell Biol. 186, 589-600 (2009).

66. Labute, P. The generalized Born/volume integral implicit solvent model: estimation of the free energy of hydration using London dispersion instead of atomic surface area. J. Comput. Chem. 29, 1693-1698 (2008).

67. Case, D. et al. AMBER 2015. (University of California, San Francisco, 2015).

68. Wang, J., Wolf, R. M., Caldwell, J. W., Kollman, P. A. \& Case, D. A. Development and testing of a general amber force field. J. Comput. Chem. 25, 1157-1174 (2004).

69. Jorgensen, W. L., Chandrasekhar, J., Madura, J. D., Impey, R. W. \& Klein, M. L. Comparison of simple potential functions for simulating liquid water. $J$. Chem. Phys. 79, 926-935 (1983).

70. Case, D. et al. Amber Tools 14. (University of California, San Francisco, 2015).

71. Bakan, A., Meireles, L. M. \& Bahar, I. ProDy: protein dynamics inferred from theory and experiments. Bioinformatics 27, 1575-1577 (2011).

72. Koukos, P. I. \& Glykos, N. M. Grcarma: A fully automated task-oriented interface for the analysis of molecular dynamics trajectories. J. Comput. Chem. 34, 2310-2312 (2013).

\section{Acknowledgements}

This work was supported by NIH grants AI083387 (to S.B) and AR054184 (to J.C.R.J). J. A.S. was supported by NIH training grant 5T32AI007271. We would like to thank Dr. David J. Prieur (WSU) for critically reading the manuscript. We also like to thank Bhim Thapa for technical assistance.

\section{Author contributions}

Experiments were conceived and designed by S.B., J.C.R.J. and S.N. The experiments were performed by S.M.P., N.K.S., J.B.G., Z.T.C., S.T., J.A.S. and T.C. S.B., J.C.R.J., S.N.,
S.M.P., N.K.S., J.B.G., Z.T.C., S.T. and J.A.S analyzed and interpreted the data. The paper was written by S.B., J.C.R.J. and S.N.

\section{Additional information}

Supplementary Information accompanies this paper at https://doi.org/10.1038/s41467019-09453-x.

Competing interests: The authors declare no competing interests.

Reprints and permission information is available online at http://npg.nature.com/ reprintsandpermissions/

Journal peer review information Nature Communications thanks Derek Abbott and the other anonymous reviewer(s) for their contribution to the peer review of this work.

Publisher's note: Springer Nature remains neutral with regard to jurisdictional claims in published maps and institutional affiliations.

\section{(c) (i)}

Open Access This article is licensed under a Creative Commons Attribution 4.0 International License, which permits use, sharing, adaptation, distribution and reproduction in any medium or format, as long as you give appropriate credit to the original author(s) and the source, provide a link to the Creative Commons license, and indicate if changes were made. The images or other third party material in this article are included in the article's Creative Commons license, unless indicated otherwise in a credit line to the material. If material is not included in the article's Creative Commons license and your intended use is not permitted by statutory regulation or exceeds the permitted use, you will need to obtain permission directly from the copyright holder. To view a copy of this license, visit http://creativecommons.org/ licenses/by/4.0/.

(C) The Author(s) 2019 